This is the final peer-reviewed accepted manuscript of:

Palermo, Michele, Stefano Silvestri, Luca Landi, Giada Gasparini, and Tomaso Trombetti. "A "direct Five-step Procedure" for the Preliminary Seismic Design of Buildings with Added Viscous Dampers." Engineering Structures 173 (2018): 933-50.

The final published version is available online at:

https://doi.org/10.1016/i.engstruct.2018.06.103

Rights / License:

The terms and conditions for the reuse of this version of the manuscript are specified in the publishing policy. For all terms of use and more information see the publisher's website.

This item was downloaded from IRIS Università di Bologna (https://cris.unibo.it/)

When citing, please refer to the published version. 


\title{
A "direct five-step procedure" for the preliminary seismic design of buildings with added viscous dampers
}

\author{
Michele Palermo (1), Stefano Silvestri, Luca Landi, Giada Gasparini and Tomaso Trombetti \\ Department DICAM, University of Bologna, Viale Risorgimento 2, 40136 Bologna, Italy
}

\begin{abstract}
In the present work a direct procedure for the preliminary seismic design of building structures with added dampers is described which represents the simplification of the so-called "five-step procedure" originally developed in 2010 by some of the authors. The procedure is applicable to yielding frame structures with a generic along-the-height distribution of inter-storey viscous dampers. It is aimed at guiding the structural engineer through the sizing of both viscous dampers and structural elements making use of an equivalent static analysis approach. First, the peak structural response under earthquake excitation is reduced by imposing an overall reduction factor accounting for both the ductility demand and the viscous damping provided by the added dampers. Second, linear damping coefficients are calculated in order to reduce the structural response according to the selected target damping ratio. Then, analytical formulas allow the estimation of peak velocities and forces in the dissipative devices, and an energy criterion is used to identify the non-linear mechanical characteristics of the actual manufactured viscous dampers. Finally, the internal actions in the structural elements are estimated through the envelope of two equivalent static analyses (ESA). At this initial stage of the research, the procedure appears suitable for the preliminary design phase, while correction factors for the higher modes contributions needs to be applied to improve its accuracy, especially for high-rise buildings. A numerical verification of the final behaviour of the system by means of non-linear time-history analyses is recommended. An applicative example is finally developed to highlight the soundness of the procedure.
\end{abstract}

\section{Introduction}

For many years, since the early developments of modern earthquake engineering in the ' $60 \mathrm{~s}$, the seismic analysis-design of buildings has been carried out using methods essentially based on the concept of equivalent lateral forces. Nowadays, much more sophisticated analysis tools, such as nonlinear dynamic

${ }^{1}$ Corresponding author. Phone: +39 051209 3232; Fax: +39 051209 3236; e-mail: michele.palermo7@unibo.it 
analyses, are available also in commercial software, and often professional engineers analyze and design building structures making use of such numerical tools. Nonetheless, actual seismic codes still admit the use of equivalent static analysis for the design of relatively regular and simple structures (CEN 2003, NTC 2008). Furthermore, equivalent static analyses are particularly useful for preliminary design, since they permit a fast evaluation of the magnitude of internal actions in the structural members and their pre-sizing necessary for the development of finite element models and for the computation of the detailed structural response with non-linear dynamic analyses.

The use of dynamic analyses for major structures was first introduced in 1974 by the SEAOC Code (Seismology Committee 1974) which recommended its use for "structures with highly irregular shapes, large differences in lateral resistance or stiffness between adjacent storeys" (Green 1987). Later on, with the rapid development of computer programs, the use of dynamic analyses has been established as standard practice for the seismic design of building structures. As such, when in the ' 80 s novel technologies for the seismic protection of buildings, such as seismic isolation and dissipative devices, were first adopted in the practice, the use of computer based simulations for the design of structures incorporating such new technologies appeared an obvious choice. Fundamental research works devoted to the development and evaluation of procedures for analysis and design of buildings with passive energy dissipation systems were carried out from the 1990s at the University at Buffalo (Constantinou and Symans 1992 and 1993, Ramirez et al. 2002 and 2003, Whittaker et al. 2003). The works are summarized in MCEER-00-0010 report (Ramirez et al. 2001) and ASCE 7-16, Chapter 18 (ASCE 2016) procedures, which are nowadays used in USA by professional engineers. Later on, most of the research works on viscous dampers (Takewaki 1997, 2000 and 2009, Shukla and Datta 1999, Lopez Garcia 2001, Singh and Moreschi 2002, Levy and Lavan 2006) basically proposed sophisticated numerical algorithms for dampers optimization (i.e. dampers size and location), sometimes leading to complex design procedures.

Alternative approaches leading to design procedures for the sizing of viscous dampers have been proposed in the last years: (i) Lopez-Garcia in 2001 (Lopez Garcia 2001) developed a simple algorithm for optimal damper configuration (placement and properties) in MDOF structures, assuming a constant inter-storey height and a straight-line first modal shape; (ii) Christopoulos and Filiatrault in 2006 (Christopoulos and Filiatrault 2006) suggested a design approach for estimating the damping coefficients of added viscous dampers consisting in a trial and error procedure; (iii) Silvestri et al. in 2010 (Silvestri et al. 2010) proposed a direct design approach, referred to as the "five-step procedure".

In the present work, a simplified procedure for the sizing of viscous dampers and structural elements of framed structures equipped with inter-storey viscous dampers is presented. The procedure is grounded on some previous works by the authors (Trombetti and Silvestri 2004, 2006, Palermo et al 2013a, 2013b and 2016) since it collects and exploits all fundamental results in the framework of the original "five-step procedure" (Silvestri et al. 2010). The procedure, originally developed for elastic frames equipped with viscous dampers, is extended to the case of yielding structures making use of an overall reduction factor 
(Palermo et al 2013a). It also takes advantages from a recent study by the authors aimed at obtaining analytical estimations of peak displacements and velocity profiles of frame structures under earthquake excitation. As such, the new procedure does not require the development of any time consuming non-linear time-history simulations for the sizing of the non-linear dampers, differently from the original five-step procedure. In addition, a step for the estimation of the maximum internal action in the structural members, within the contest of Equivalent Static Analyses (ESA), is introduced representing the main novelty of the work. It should be acknowledged that, at this stage of the research, the procedure appears suitable for the preliminary design phase since correction factors to improve its accuracy still need to be calibrated. In any case, numerical verification by means of more complex and detailed design procedures such as those described in chapter 18 of ASCE 7-16 is recommended for the final design phase.

In this work, the procedure is first presented in the most general case, e.g. a generic frame structure with a generic along-the-height disposition of inter-storey viscous dampers placement. Then, it is specified to an idealized uniform frame building with uniform dampers placed at all storeys. Indeed, this idealized case allows for a fully analytical description of the seismic response of the structure and to derive considerations on the behaviour trends and useful indications on the costs/benefits relationships.

\section{Current code provisions for structures equipped with added dampers}

Many guideline documents have been published in different countries, such as FEMA-273 and FEMA-274 (BSSC 1997a, 1997b), NEHRP 2000 Provisions/FEMA-368 (BSSC 2001), NEHRP 2003 Provisions/FEMA 450: Chapter 15 - Structures with Damping Systems (BSSC 2004), Eurocode 8: Design of Structures for Earthquake Resistance - Part 1 (CEN 2003), ASCE 7-16: Seismic Provisions: Chapter 18 - Seismic Design Requirements for Structures with Damping Systems (ASCE 2016), JSSI Manual: Design and Construction Manual for Passively Controlled Buildings (JSSI 2003, 2007).

Although the design procedures vary in different standards, they are all based on: equivalent lateral force methods, response spectrum modal analysis method, non-linear time-history simulations. Among above guidelines, only the American and Japanese codes provide detailed instructions for the analyses and design of buildings with viscous dampers. Indeed, according to Christopoulos and Filiatrault (2006), Japan and USA were the only countries with numerous real implementations of viscous dampers in structures up to 2003, with the first applications back to the end of the '80s. On the contrary, European countries have much less and recent cases of practical implementation of viscous dampers in structures. The main reason of this very limited application of viscous dampers in Europe could be the lack of specific design procedures and recommendations in Eurocode 8. 


\subsection{ASCE 7-16}

Chapter 18 of ASCE 7-16 is dedicated to the design of buildings with damping systems. Both linear and nonlinear design procedures are presented. In detail, an Equivalent Lateral Force (ELF) procedure is permitted to be used for regular structures (in-plan and in-elevation) and for structures not exceeding $30 \mathrm{~m}$ height. The ELF procedure is based on the residual mode approach (Ramirez et al. 2003) and considers also yielding buildings. The structural response is calculated as the combination of the fundamental modes response and the residual modes response according to the SRSS combination rule.

Seismic response coefficients $\left(C_{S 1}\right.$ and $\left.C_{S R}\right)$ are introduced to account for the reduction of the seismic response (e.g. base shear) due to both the damping provided by the added damping devices and the hysteretic damping due to the yielding of the structural members. The seismic response coefficients $C_{S 1}$ and $C_{S R}$ are used to estimate the seismic base shear associated to the first mode $\left(V_{1}\right)$ and to the residual modes $\left(V_{R}\right)$. The seismic base shear associated to the first and the residual modes are then used to compute the design lateral forces (e.g. the equivalent static forces) which are applied at each floor in order to design the structural elements of the seismic force-resisting systems (e.g. typically columns and beams for frame structures).

The design forces in the damping devices are evaluated on the basis of floor deflections and storey velocities, which are calculated using the first mode roof displacement $\left(D_{1 D}\right)$ and the residual mode roof displacement $\left(D_{R D}\right)$ due to the design earthquake, together with the first mode shape $\left(\phi_{i 1}\right)$ and the residual modes shapes $\left(\phi_{i R}\right)$.

The mode properties (i.e. mode shapes and periods of vibration), which are required to develop the ELF procedure, shall be calculated either by dynamic analysis (typically requiring the development of a Finite Element model) or using simplified equations.

The ELF procedure can be rigorously and efficiently implemented in a computer code and has been satisfactory validated by means of various applicative examples, as the sample 3- and 6- storey frames reported in the work by Ramirez et al. (2003).

\subsection{JSSI Manual}

JSSI Manual provides relatively specific instructions for distributing viscous dampers along-the-height of a structure. The main design process is described in the work by (Kasai and Kibayashi 2004). It is based on the use of performance curves which are derived based on an equivalent SDOF system schematization. The curves displays both displacement reduction ratio and force (or acceleration) reduction ratio that are defined as the values of the peak responses normalized to those of the same structure with no dampers. In particular the performances are evaluated in terms of the so called "storage stiffness" and "loss stiffness" calculated considering the two instants of peak deformation and zero deformation.

Firstly, for a given earthquake input of a smooth response spectrum, the peak displacement and the base shear of a frame prior to damper placement are predicted from the response spectrum. Then, the target 
reduction ratios of displacement and base shear are estimated based on the required performance. Finally, with the target reduction ratios and the performance curve, the necessary stiffness of viscous dampers and braces are determined.

An optimum design solution to control both displacement and force is obtained from the performance curve. However, it is noted that the performance curves are given based on the SDOF system and therefore, the design of viscous dampers in a multi-storey case needs to be conducted by modelling the MDOF frame using an equivalent SDOF system. The principle of the distribution of total viscous dampers to every storey is that the damper loss stiffness, defined as the force at zero displacement divided by the peak deformation in steady-state response of the viscous damper (JSSI 2007), shall be proportional to the corresponding storey stiffness of the MDOF system.

Nonetheless, as observed in the work by (Weng et al. 2012) the design of damped structures in the JSSI Manual is implemented based on performance curves, which are drawn according to the statistic regression of data from Japanese earthquakes. Thus, their applicability to other countries is not straightforward.

\subsection{EC8}

Eurocode 8 does not provide any specific design procedure for buildings with added viscous dampers. As such, the only analysis method which is suitable for this class of structure is the non-linear time-history analysis. In this case the structure response is obtained through direct numerical integration of the differential equation of motion, using a set of accelerograms representative of the ground motion at the site. The structural elements and the viscous dampers should be modelled in order to represent their non-linear cyclic behavior and energy dissipation in the whole range of displacement and velocity amplitudes expected in the seismic design scenario.

\section{The "direct five-step procedure": overview}

In the present section the proposed design procedure for the sizing of viscous dampers and structural elements in framed structures, hereafter referred to as "direct five-step procedure", since it is grounded on the original "five-step procedure" proposed by some authors in 2010 (Silvestri et al. 2010), is summarized. Its main purpose is to guide the structural engineer through the sizing of both the viscous dampers and the structural elements within the framework of equivalent static analysis method. It is applicable to inelastic frame structures equipped with a generic along-the-height distribution of inter-storey viscous dampers. The procedure should be carried out separately along the two directions of the $3 \mathrm{D}$ building structure, since it is developed with reference to a 2D model.

Figure 1 provides a flow chart of the "direct five-step procedure". It integrates some results of previous research works developed by the authors (Trombetti and Silvestri 2004 and 2006, Silvestri et al. 2010, 
1 STEP 1, the performance objective are identified by imposing a target reduction factor of the elastic 2 spectrum (input energy) through both energy dissipated by the viscous dampers (quantified by an equivalent 3 damping ratio) and hysteretic energy dissipated by the structure (quantified by means of the behaviour factor $4 q$ related to the ductility demand $\mu$ ). Once the desired performances are identified, in STEP 2 the equivalent 5 linear dampers are sized, while in the STEP 3 the peak inter-storey drifts, peak inter-storey velocities and 6 peak damper forces expected with the design earthquake are estimated. These estimations are used to size the 7 commercial viscous dampers typically characterized by non-linear behaviour (STEP 4) and then to perform 8 two equivalent static analyses (namely ESA1 and ESA2), whose results envelope allows the sizing of the 9 structural elements (STEP 5). The rationale behind the use of the results envelope of the two equivalent static 10 analyses ESA1 and ESA2 is explained in Appendix 1 with reference to the coupled dynamic response of a 11 portal frame equipped with an inclined viscous damper. Each step of the procedure is detailed in the next 12 sections.

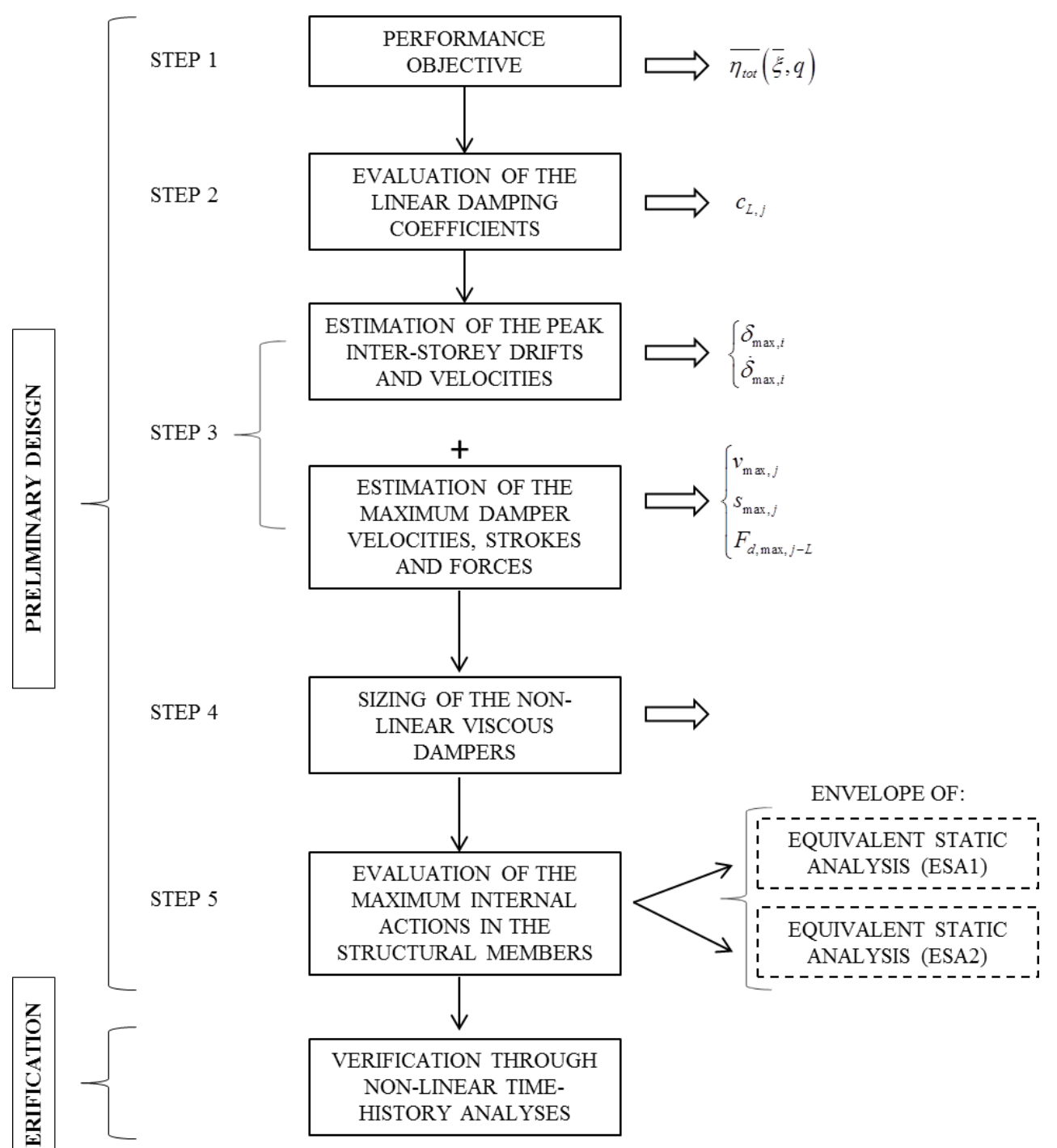

Figure 1: Flowchart of the "direct five-step procedure". 
In STEP 1, the target $x \%$ reduction of the elastic base shear corresponding to a desired overall reduction factor is evaluated: $\overline{\eta_{t o t}}=1-x / 100$. The damping ratio corresponding to $\overline{\eta_{t o t}}=1-x / 100$ is referred to as the 4 target damping ratio $\bar{\xi}$.

$$
\eta_{t o t}(\xi, q)=\eta_{\xi} \cdot \eta_{q}=\sqrt{\frac{10}{5+\xi}} \cdot\left(\frac{1}{q} \cdot \frac{1}{\psi(\xi, q)}\right)
$$

where $q$ is the behaviour factor, related to allowable excursion in the inelastic field (ductility demand). When linear elastic response of the structural elements is considered $(q=1), \eta_{q}=1$ and Eq. (1) reduces to the wellknown formulation by Bommer et al. 2010:

$$
\eta(\xi)=\sqrt{\frac{10}{5+\xi}}
$$

Typically, the values of $q$ are given by codes and refer to structures with no damping devices. $\psi(\xi, q)$ is a coupling coefficient which has been calibrated based on extensive numerical simulations on highly damped elastic-plastic SDOF systems subjected to earthquake ground motions (note that in the work Palermo et al. (2013b) it is referred to as " $\alpha$ "). For instance, the trend of $\psi$ with respect to the natural period of the SDOF system $T$ and the behaviour factor $q$ is shown in Figure 2 a for a fixed value of $\xi=30 \%$. Given that $\psi$ oscillates around 1.0, in the preliminary design phase, as a first approximation, a unitary value is allowable to be used.

For instance, elastic and inelastic design spectra for two values of damping ratio ( $\xi=5 \%$ and $\xi=30 \%$ ) and $q=4$ are represented in Figure $2 \mathrm{~b}$. The amplitudes of the inelastic spectra are obtained by reducing the corresponding elastic spectra by the total reduction factor according to Eq. (1) with $\psi(\xi, q)$ set equal to 1.0. Four different spectra result:

- $S_{\mathrm{e}, 5 \%}$ is the elastic spectrum at $5 \%$ damping ratio.

- $S_{\mathrm{e}, \bar{\xi}}$ is the elastic spectrum for a target damping ratio $\bar{\xi}$ (30\% in Figure $2 \mathrm{~b}$ ). 


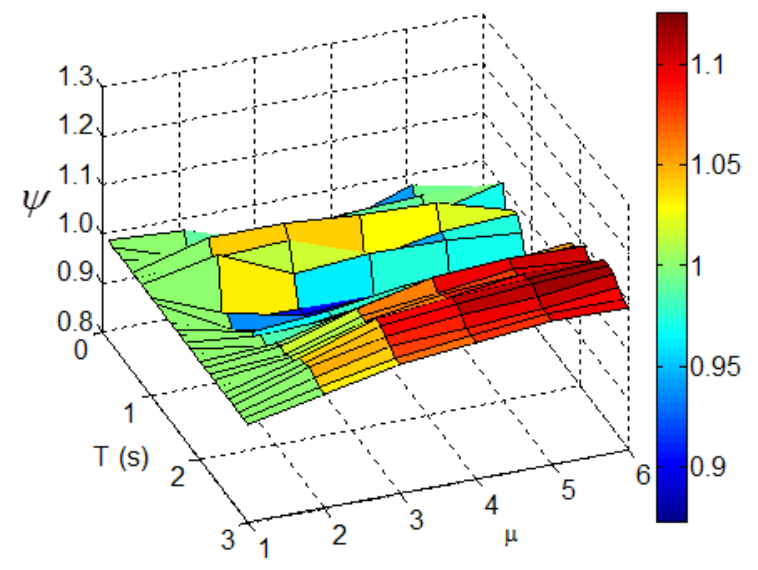

(a)

- $S_{d .5 \%}$ is the inelastic (or design) spectrum at 5\% damping ratio.

- $S_{d, \bar{\xi}}$ is the inelastic (or design) spectrum for a target damping ratio $\bar{\xi}$ (30\% in Figure $2 \mathrm{~b}$ ).

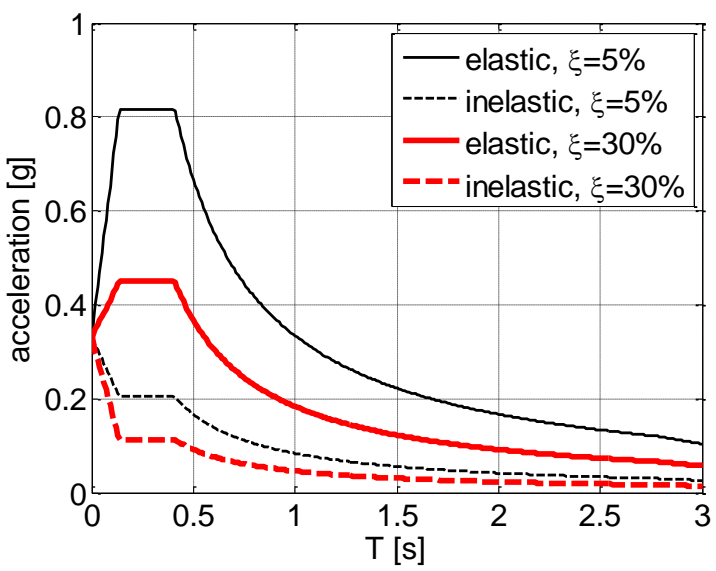

(b)

Figure 2: (a) Surface of $\psi$ coefficient (adapted from Palermo et al. 2013b); (b) elastic and inelastic design spectra.

\section{STEP 2: the sizing of the inter-storey linear viscous dampers}

In STEP 2, the values of the linear damping coefficient $c_{L, j}$ of each viscous damper $(j$ indicates the generic $j$-th damper) corresponding to the target reduction factor are evaluated. Note that, at this step, the dampers are assumed to be characterised by a linear force -velocity $\left(F_{d}-v\right)$ relationship of the type $F_{d}=c_{L} \cdot \operatorname{sign}(v) \cdot|v|$. The sizing of the inter-storey viscous dampers is here conducted making use of the fivestep procedure developed by the authors in 2010 (Silvestri et al. 2010). It allows to obtain the values of the damping coefficients of the equivalent linear viscous dampers $c_{L, j}$ in terms of the target response reduction factor $\overline{\eta_{t o t}}$ through simple analytical formulas. In its original form, the procedure has been derived for the case of uniform along-the-height dampers inserted into shear-type buildings, encompassing both the cases of dampers placed so that one end is connected to the structure while the other end is connected to a fixed point (typically the ground or a very stiff structure) in a so called "fixed-point placement" and the more usual case of dampers located between two adjacent storey in a so called "inter-storey placement". Nonetheless, its effectiveness has been also proved for not uniform damper placements and generic moment-resisting type frames which are characterized by non-classical damping (Palermo et al. 2013a). In particular, the case of inter-storey diagonal placement is here considered. Figure 3 displays a generic viscous damper inserted within two adjacent floors, e.g. the $i$-th storey. $h_{i}$ and $B$ are the $i$-th inter-storey height and the bay width 
respectively, $\theta_{j}$ indicates the inclination of the $j$-th damper with respect to the horizontal direction, $s_{j}$ is the stroke of the $j$-th damper related to the $i$-th inter-storey drift $\delta_{i}$ and the $j$-th angle $\theta_{j}$. Once the along-theheight relative distribution of dampers has been assumed (typical distributions are uniform, stiffness proportional, proportional to maximum inter-storey drifts of the naked structure), the following equation can be used to obtain the values of each linear damping coefficient:

$$
\sum_{j=1}^{n_{t o t}} c_{L, j} \cdot \cos \left(\theta_{j}\right)^{2}=\bar{\xi}_{v} \cdot \omega_{1} \cdot m_{t o t} \cdot N \cdot(N+1)
$$

where $\omega_{1}=2 \pi / T_{1}$ is the first mode circular frequency of the structure; $m_{t o t}$ is the total building mass, $N$ is the total number of storeys of the building; $n_{\text {tot }}$ is the total number of viscous dampers introduced in the whole building along one direction. Eq. 3 is grounded on the approximate relationship $\frac{k}{m \cdot \omega_{1}^{2}} \cong \frac{N(N+1)}{2}$ derived by Trombetti and Silvestri (2006) studying the modal properties of uniform shear-type frames with constant lateral storey stiffness $k$ and constant floor mass $m$. In detail, the authors studied the properties of the SPD and the MPD matrices of uniform shear type frames and derived analytical expressions to relate the total damping coefficient $c_{t o t}$ (that is the sum of the damping coefficients of all dampers ) with the first modal damping ratio.

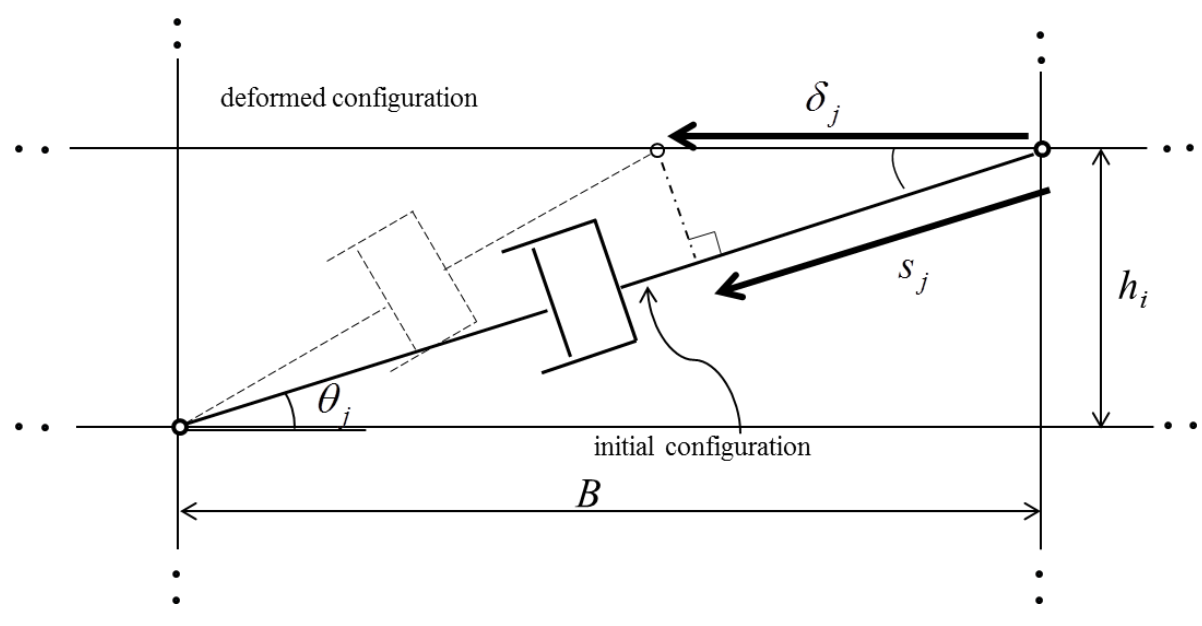

Figure 3: Inter-storey diagonal viscous damper placement (deformed configuration is highly magnified).

\section{STEP 3: an estimation of maximum damper velocities and damper forces}

In STEP 3, the peak inter-storey drifts $\delta_{\text {max }, i}$ and velocities $\dot{\delta}_{\max , i}$, the maximum damper velocities $v_{\max , j}$, forces $F_{D \max , j-L}$ and strokes $S_{\max , j}$ under the design earthquake are evaluated. Such response quantities can 
1 be estimated following to procedure recently proposed by the authors (Palermo et al. 2016). In detail, assuming that the building structure will respond mainly according to its first mode of vibration $\{\phi\} \cong\left\{\phi^{1}\right\}$, an estimation of the maximum floor lateral displacements $\phi_{\max , i}=\beta \cdot \phi_{i}$ ( $\beta$ is a constant to be determined) is

4 obtained by imposing the global equilibrium along the horizontal direction between the total base shear (

$\left.5 \lambda \cdot m_{t o t} \cdot S_{e, \xi}\left(T_{1}\right)\right)$ and the sum of the inertial forces $\left(\sum_{i=1}^{N} m_{i} \cdot \ddot{\phi}_{\max , i}\right)$

$$
\lambda \cdot m_{t o t} \cdot S_{e, \xi}\left(T_{1}\right)=\sum_{i=1}^{N} m_{i} \cdot \ddot{\phi}_{\text {max }, i}
$$

Assuming that:

$$
\ddot{\phi}_{\max , i}=\omega_{1}^{2} \cdot \phi_{\max , i}
$$

the substitution of Eq. (5) into Eq. (4) leads to the following equation in the unknown $\beta$ which provides the amplitudes of all inter-storey drifts:

$$
\lambda \cdot m_{t o t} \cdot S_{e, \bar{\xi}}\left(T_{1}\right)=\beta \cdot \omega_{1}^{2} \cdot \sum_{i=1}^{N} m_{i} \cdot \phi_{i}
$$

where: $S_{e, \bar{\xi}}\left(T_{1}\right)$ is the ordinate of the elastic pseudo-acceleration spectrum at the fundamental period of the structure $T_{1} ; m_{i}$ is the floor mass at the $i$-th storey and $\lambda$ a coefficient accounting for the reduced contribution of the first mode in comparison with the total mass; values of $\lambda$ depends on $T_{1}$ and the structural configuration; EC8 suggests a value of $\lambda=0.85$ for regular frames with at least three storeys and fundamental period $T_{1}<2 T_{c}$ (in other cases $\lambda=1.0$ is suggested). $T_{c}$ is the period corresponding to the beginning of constant displacement spectral range.

From the peak floor displacements $\phi_{\max , i}$ it is then possible to obtain the peak inter-storey drifts $\delta_{\max , i}$ and the peak inter-storey velocities $\dot{\delta}_{\max , i}$, as well as the maximum damper velocities $v_{\max , j}$, strokes $s_{\max , j}$ and forces $F_{D \text { max }, j-L}$ (subscript $L$ stands for linear damper) using the following relationships:

$$
\delta_{\max , i}=\phi_{\max , i}-\phi_{\max , i-1}
$$

$$
\dot{\delta}_{\text {max }, i}=\omega_{1} \cdot M_{i} \cdot r_{i} \cdot \delta_{\text {max }, i}
$$

$$
v_{\max , j}=\dot{\delta}_{\max , i} \cdot \cos \theta_{j}
$$




$$
s_{\max , j}=\delta_{\max , i} \cdot \cos \theta_{j}
$$

$$
F_{D \max , j-L}=c_{L, j} \cdot v_{\max , j}
$$

In Eq. (8) $M_{i}$ is a coefficient recently introduced by the authors (Palermo et al. 2016) which accounts for (i) the discrepancies between the actual velocities and the pseudo-velocities (first highlighted by Peckan et al. (1999)) and (ii) the contribution of the higher modes in the peak velocities. $M_{i}$ values mainly depend on the value of the first mode of vibration $T_{1}$ (they tend to linearly increase with $T_{1}$ ) but they are also affected by (i) the main characteristics of the earthquake input, and (ii) the along-the-height stiffness and damping distribution. In two recent works (Palermo et al. 2015, Palermo et al. 2017), the authors focused on the evaluation of the trends of $\lambda$ and $M_{i}$ for the class of linear elastic uniform shear frame buildings (e.g. sheartype frame structures with constant floor mass and lateral storey stiffness at all storeys) showing that large $M_{i}$ are generally observed at the bottom storeys (maximum values around 2.5 for a structure with $T_{1}=5 \mathrm{~s}$ ). In these works, the authors have calibrated two linear regression equations for the magnification factor at the ground storey $M_{l}$ (Figure 4). The discrepancies between the two predictions are due to both the ground motion properties and frame properties. Coefficient $r_{i}$ accounts for the effect of eventual inelastic behaviour For linear elastic structures: $r_{i}=1$. In presence of inelastic behaviour, in general the effect is a reduction of the velocities (Ramirez et al. 2001). Nonetheless, a more extensive parametric study (out of the scope of the present work) is required to evaluate the trends of these coefficients, accounting for different structural configurations and damping systems.

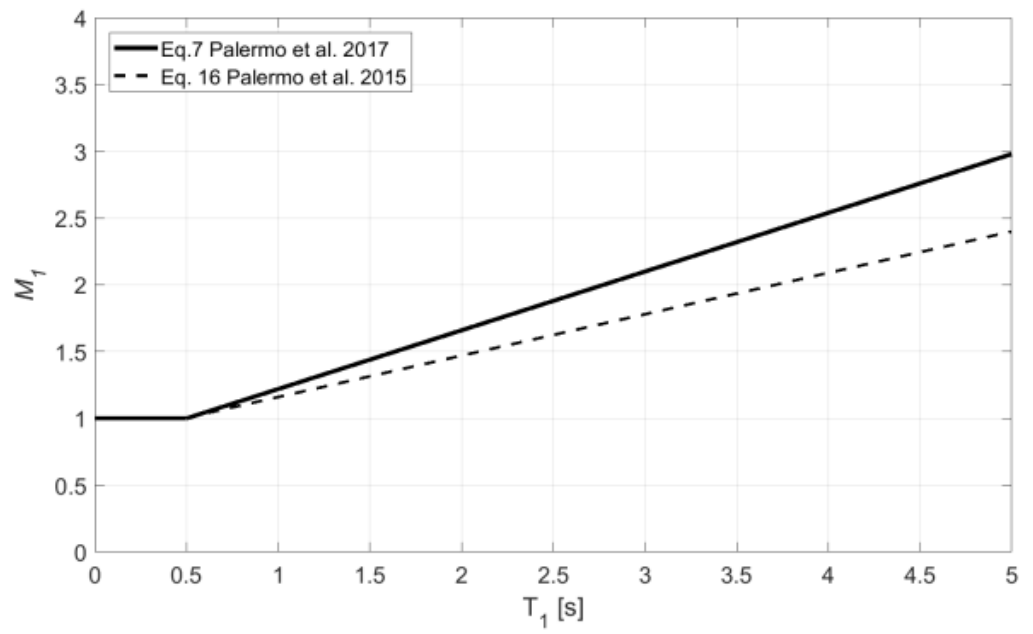

Figure 4: Linear-regression equations for coefficient $M_{l}$ (adapted from Palermo et al. 2017).

Moreover, in presence of significant excursion in the inelastic field, the peak velocities tend to reduce (this effect can be related to the increase in the fundamental period of vibration, $T_{\text {eff }}=T_{1} \cdot \sqrt{\mu}$, as a function of the ductility ratio $\mu$ (Ramirez et al. 2001)). Nonetheless, a more extensive parametric study (out of the scope of 
the present paper) is required to evaluate the trends of these coefficients, for example for other structural configurations.

\section{STEP 4: the sizing of the non-linear commercial dampers}

In STEP 4, the characteristics of the non-linear commercial dampers are determined. The commercial dampers are typically characterized by exponential non-linear force-velocity response with values of the damping exponent $\alpha$ generally less than $1.0(0.15 \div 0.30$ are the most common values):

$$
F_{D-N L}=c_{N L} \cdot \operatorname{sigh}(v) \cdot|v|^{\alpha}
$$

In detail, the following relationship, based on an equivalence of energy dissipated within a cycle (Silvestri et al (2010)), can be used to obtain the non-linear damping coefficient of each damper (Figure 5):

$$
c_{N L, j}=c_{L, j} \cdot\left(0.8 \cdot v_{\max , j}\right)^{1-\alpha}
$$

Eq. 13 can be interpreted as follows: the damping coefficient of the non-linear damper characterized by law values of damper exponent (say $\alpha \cong 0.15-0.30$ ) can be obtained in terms of the damping coefficient of the corresponding linear damper using a "design velocity" equal to $00.8 \cdot v_{\max , j}$.

Then, assuming that the maximum velocity developed in the non-linear commercial damper will be equal to the one of the corresponding linear damper calculated according to Eq. 9, substitution of equation 13 into Eq. 12 leads to the following estimation of the maximum force in each $j$-th non-linear commercial damper:

$$
F_{D \max , j-N L}=0.8^{1-\alpha} \cdot F_{D \max , j-L}
$$

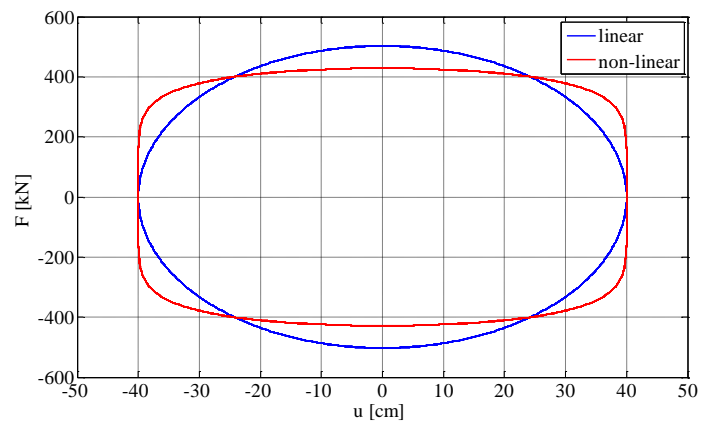

(a)

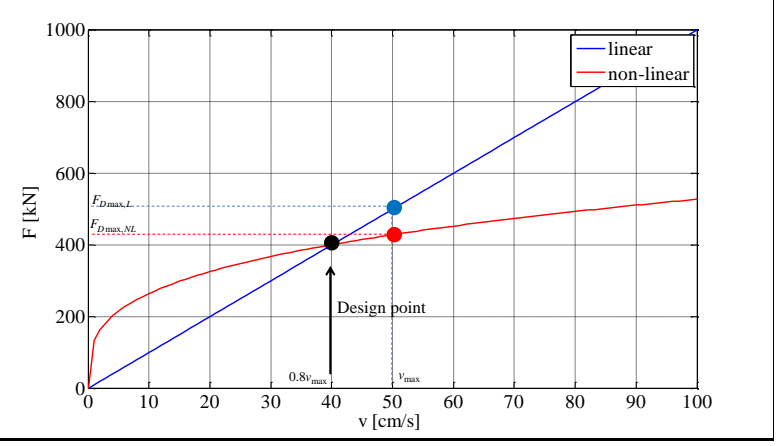

(b)

Figure 5: (a) Force-displacement response of linear and corresponding non-linear viscous damper; (b) forcevelocity response of linear and corresponding non-linear viscous damper.

In order to maintain high efficiency of the device, the axial stiffness of the dissipative brace (the stiffness due to the compressibility of the oil in the chamber of the damper in series with the stiffness of the supporting brace) should satisfy the following indication (Silvestri at al (2010)): 


\section{STEP 5: the design of the structural members: ESA1 and ESA2}

In STEP 5, the maximum internal actions in the structural elements are estimated through the envelope of two Equivalent Static Analyses. It is known that during an earthquake the internal seismic induced actions in the structural members (such as columns and beams) achieve their maximum values at the time instant of maximum lateral displacements. On the contrary, the forces in the viscous dampers achieve their maximum values at the time instant of maximum inter-storey velocities, which is roughly coincident with the instant of zero lateral deformation. In case of the typical inter-storey dampers placement, the axial forces in the dampers induce additional axial forces in beams and columns, which may govern the entire structural design. Therefore, the maximum internal actions in the structural members can be estimated from the envelope of the following two equivalent static analyses, namely:

- ESA1: is the static analysis of the naked structure performed with a set of external horizontal forces leading to internal actions in the structural members coherent with the peak internal flexural actions generated during an earthquake, e.g. at the time instant of maximum lateral deflection.

- ESA2: is the static analysis performed on an appropriate structure schematization which provides the internal actions in the structural members coherent with the maximum actions transferred by the dampers during an earthquake, e.g. at the time instant of maximum lateral velocity.

More detailed explanations of the rationale behind the use of the envelope of the two equivalent static analyses ESA1 and ESA2 is given in Appendix 1 with reference to the dynamic behaviour of a simple onestorey portal frame equipped with a diagonal viscous damper.

\subsubsection{Equivalent Static Analysis at the instant of maximum lateral deformation: ESA1}

The equivalent static analysis ESA1 is conducted by applying to the naked structure the following set of lateral forces according to the well-established procedures implemented in all seismic building codes:

$$
F_{E S A 1, i}=F_{h} \cdot \frac{z_{i} \cdot m_{i}}{\sum_{k=1}^{N} z_{k} \cdot m_{k}}
$$

where $z_{i}$ is the height of the $i$-th storey from the foundation level and $F_{h}$ is:

$$
F_{h}=\lambda \cdot S_{d, \bar{\xi}}\left(T_{1}\right) \cdot m_{t o t}
$$

Note that, when added viscous dampers are inserted into existing structures the value of the spectral acceleration which is used to perform the equivalent static analysis ESA1 cannot be, in general, evaluated according to the step 1 of the procedure. Indeed, the approach that has been adopted to derive the overall 

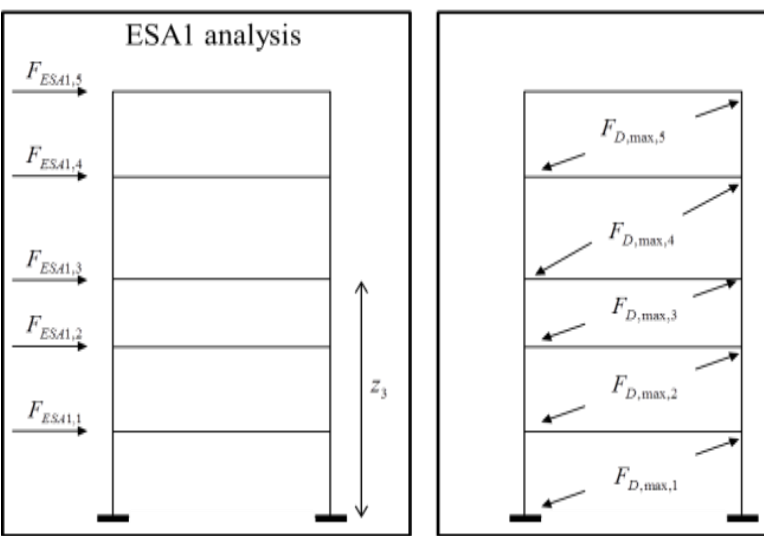

$$
F_{E S A 2, i}=F_{D \max , i} \cdot \cos \theta_{i}-F_{D \max , i+1} \cdot \cos \theta_{i+1}
$$
demand between the damped structure to be designed and the corresponding bare frame structure under the same earthquake intensity level (the reader can refer to Palermo et al. 2014 for additional details).

\subsubsection{Equivalent Static Analysis at instant of maximum lateral velocity: ESA2}

The equivalent static analysis ESA2 is conducted by applying to the structure with dampers replaced by rigid diagonal braces the following set of lateral forces (Fig. 6):
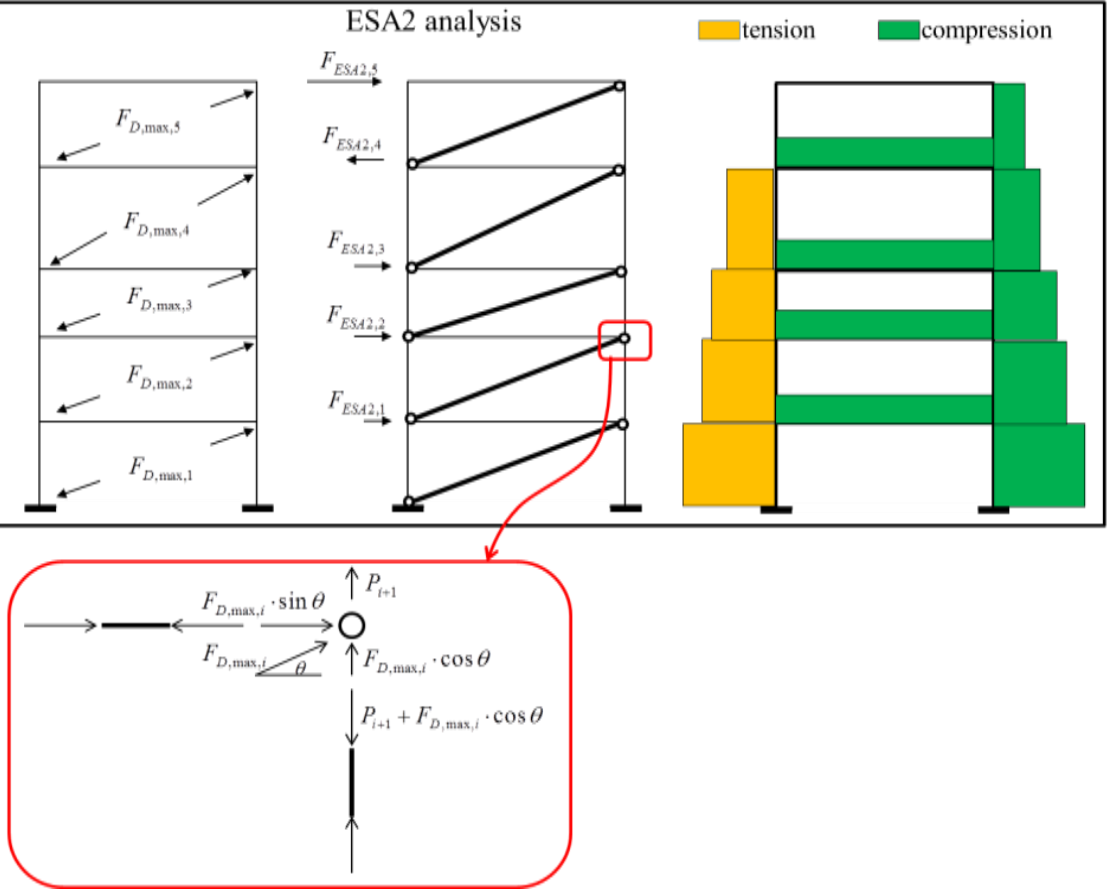

Figure 6: Equivalent static analyses ESA1 and ESA2.

The set of equivalent lateral forces of Eq.18 produces additional internal axial forces in the beams, $P_{B i}$, and columns,$P_{C i}$, (whose qualitative diagram is shown in figure 6) which can be expressed as follows:

$$
P_{B, i}=F_{D \max , i} \cdot \sin \theta_{i}
$$

$$
P_{C, i}=P_{C, i+1}+F_{D \max , i} \cdot \cos \theta_{i}
$$




\section{Final verification through non-linear time history analyses}

After the application of STEPS 1-5 the analyst has all the information necessary to develop a numerical model of the building equipped with the added viscous dampers. At this stage of the research, non-linear time-history analyses are recommended to verify the actual behaviour of the structure and eventually to provide some little adjustments to the size of dampers and structural elements to fully satisfy the design requirements or even to develop an "optimal" design. In this regard, the results obtained from STEPS 1-5 may be used as starting point for the development of more sophisticated iterative procedures for damper optimization, for instance the one proposed by Levy and Lavan (2006).

In addition, the proposed procedure could be also utilized to have a first estimation of the internal actions at the stage of maximum acceleration combining the results of the ESA1 and ESA2 with the appropriate combination coefficients tabled in the ASCE 7-16 as a function of the velocity exponent $\alpha$ and viscous damping ratio $\xi_{v}$.

\section{Analytical results for the special case of linear "uniform frames"}

\subsection{Assumptions}

The ESA procedure presented in section 3 is here specialized for the case of $N$-storey, 1-bay frame structures assuming:

- linear elastic structural behaviour $\left(q=1, S_{d, \xi}\left(T_{1}\right)=S_{e, \xi}\left(T_{1}\right)\right)$;

- floor mass $m$ and lateral storey stiffness $k$ equal at all storeys;

- inter-storey height $h$ and bay width $b$ equal at all storeys, so that the damper inclination $\theta$ remains constant along the building height;

- equal viscous dampers placed at all storeys (characterized by linear damping coefficient $c_{L}$ );

- linear deformed shape $\{\phi\}$ under earthquake ground motion;

- $\quad M_{i}=1$ at all storeys;

- $\lambda=1.0$;

Such class of frames will be refereed hereafter as "uniform frames". The above assumptions, even though rarely verified in real structures, allow to derive fully analytical relationships for the sizing of the viscous dampers, and to obtain a fully analytical description of the envelope seismic response of the system (maximum damper forces and maximum internal actions in the structural elements). The analytical developments also allow to provide some interesting observations and comparisons on the effectiveness of 
1 the added dampers. The analytical formulas related to the simplified ideal case of "uniform frames" are

2 derived in the following subsections. Discussion on the effectiveness of the added dampers is given in 3 section 10.3 .

\section{10.2. The "direct five-step procedure" for the class of "uniform frames"}

5 STEP 1:

6 Given that the frame is assumed elastic $(q=1)$, use is made of Eq. 2 which, assuming $\xi_{v}=\bar{\xi}_{v}$ corresponding to $7 \quad \bar{\xi}=\xi_{i}+\bar{\xi}_{v}=5 \%+\bar{\xi}_{v}$ specializes as follows:

8

$$
\bar{\eta}(\bar{\xi})=\sqrt{\frac{10}{5+\bar{\xi}}}=\sqrt{\frac{10}{5+5+\overline{\xi_{v}}}}
$$

9

10

11

12

13

14

15

16

17

18

$$
c_{L}=\frac{\overline{\xi_{v}} \cdot \omega_{1} \cdot m_{t o t} \cdot(N+1)}{\cos ^{2} \theta}
$$

\section{STEP 3:}

The solution of Eq. (6) under the above assumptions leads the following expression of the peak storey drifts vector $\left\{\phi_{\max }\right\}$, peak inter-storey drifts $\delta_{\max }$, peak inter-storey velocities $\dot{\delta}_{\max }$, maximum damper velocities $v_{\max }$ and maximum damper forces $F_{D \max , L}$ (the response quantities are equal at all stories):

$$
\delta_{\max }=\frac{S_{e, \bar{\xi}}\left(T_{1}\right)}{\omega_{1}^{2}} \cdot \frac{2}{(N+1)}
$$

$$
\dot{\delta}_{\max }=\frac{S_{e, \bar{\xi}}\left(T_{1}\right)}{\omega_{1}} \cdot \frac{2}{(N+1)}
$$




$$
\begin{gathered}
v_{\max }=\frac{S_{e, \bar{\xi}}\left(T_{1}\right)}{\omega_{1}} \cdot \frac{2}{(N+1)} \cdot \cos \theta \\
F_{D \max , L}=\frac{2 \cdot \overline{\xi_{v}} \cdot m_{t o t} \cdot S_{e, \bar{\xi}}\left(T_{1}\right)}{\cos \theta}
\end{gathered}
$$

4 5

6

8

9

$$
c_{N L}=\frac{\bar{\xi}_{v} \cdot \omega_{1} \cdot m_{t o t} \cdot(N+1)}{\cos ^{2} \theta} \cdot\left(0.8 \cdot \frac{S_{e, \bar{\xi}}\left(T_{1}\right)}{\omega_{1}} \cdot \frac{2}{(N+1)} \cdot \cos \theta\right)^{1-\alpha}
$$

The non-linear damping coefficient of each manufactured viscous damper can be evaluated through the following equation:

\section{STEP 5:}

The equivalent static analysis ESA1, as specialized for the class of "uniform frames", is conducted by applying to the corresponding naked structure the following set of lateral forces (Fig. 7a):

$$
F_{E S A 1, i}=\frac{2 \cdot m}{N+1} \cdot S_{e, \bar{\xi}}\left(T_{1}\right) \cdot i
$$

It can be noted that the lateral forces linearly increase going from the top to the bottom.

The equivalent static analysis ESA2, as specialized for the class of "uniform frames", is conducted by applying to the structure with dampers replaced by rigid diagonal braces the following top-storey lateral force (Fig. 7b):

STEP 4:

$$
F_{E S A 2,5}=2 \cdot \bar{\xi}_{v} \cdot m_{t o t} \cdot S_{e, \bar{\xi}}\left(T_{1}\right)
$$

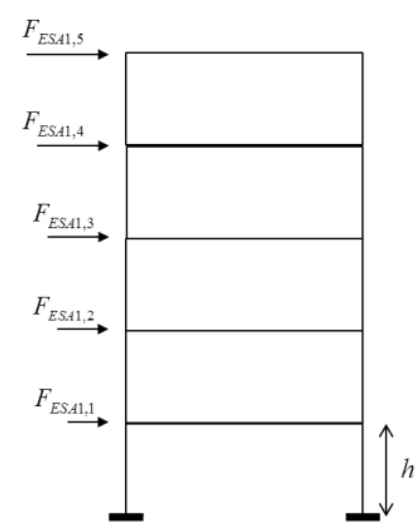

(a)

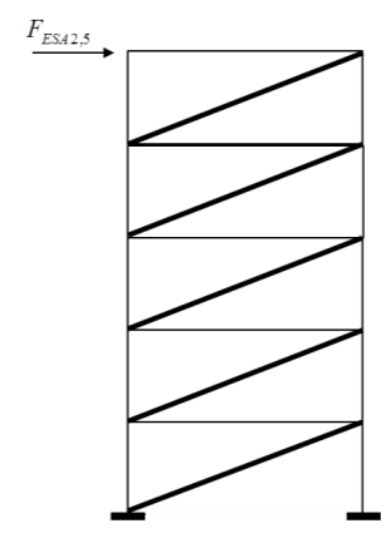

(b) 
Figure 7: Equivalent static analyses ESA1 (a) and ESA2 (b) for the special case of uniform frame.

By simple equilibrium considerations the maximum axial force in the columns also linearly increases going from the top to the bottom according to the following equation:

$$
P_{C, i}=2 \cdot \overline{\xi_{v}} \cdot m_{t o t} \cdot S_{e, \bar{\xi}}\left(T_{1}\right) \cdot \tan \theta \cdot(N-i+1)
$$

The maximum axial force (hereafter also referred to as base axial force) is achieved at the ground floor $(i=1)$ :

$$
P_{C, 1}=2 \cdot \overline{\xi_{v}} \cdot m_{t o t} \cdot S_{e, \bar{\xi}}\left(T_{1}\right) \cdot \tan \theta \cdot N
$$

\subsection{Discussion}

The analytical expressions of the maximum damper forces and maximum axial forces in the columns transmitted by the dampers allow to provide interesting comparisons.

Fig. 8 displays the maximum base shear for the damped structure, $V_{b a s e}=m_{t o t} \cdot S_{e, \xi}\left(T_{1}\right)$, the maximum damper force ( $F_{D, \max , L}$, as given by Eq. $\left.(27)\right)$, the maximum axial force at the base ( $P_{\text {base }}$, as given by Eq. (32)) as functions of the damping ratio, for $N=5$ and 10 and $\theta=30^{\circ}$. All quantities are normalized with respect to the base shear corresponding to the $5 \%$ damping ratio, $V_{\text {base }, \xi=5 \%}$. Note that the ratio $V_{\text {base }} / V_{\text {base }, \xi=5 \%}$ is coincident with the response reduction factor $\eta$.

The following observations can be made:

- as expected, with increasing damping ratio, the base shear decreases at the expense of increasing maximum damper forces and maximum axial forces. However, the maximum damper force never exceeds $V_{\text {base }, \xi=5 \%}$;

- the maximum damper force equals the base shear for $\xi$ around $35 \%$. For this specific value of damping ratio, both quantities are equal to approximately $0.5 V_{b a s e, \xi=5 \%}$;

- as expected, with increasing total number of storeys, the maximum axial force increases and may become significantly larger than $V_{\text {base }, \xi=5 \%}$ (up to 2.5 times for $N=10$ and $\xi=50 \%$ ). 


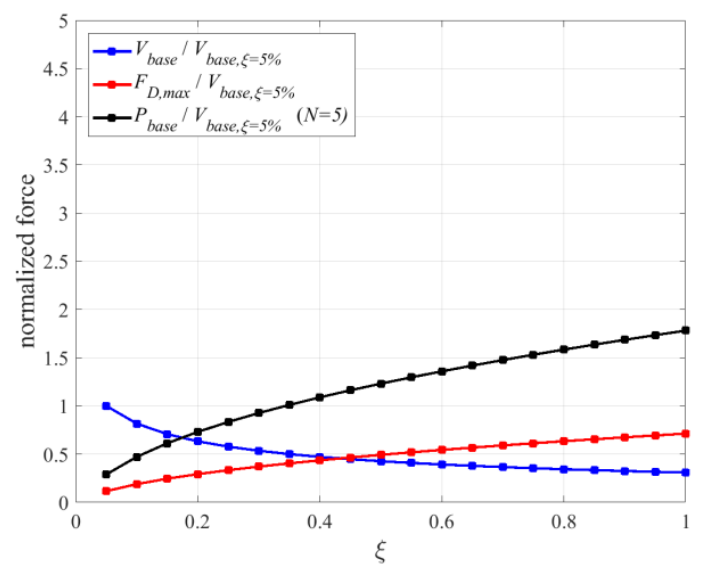

(a)

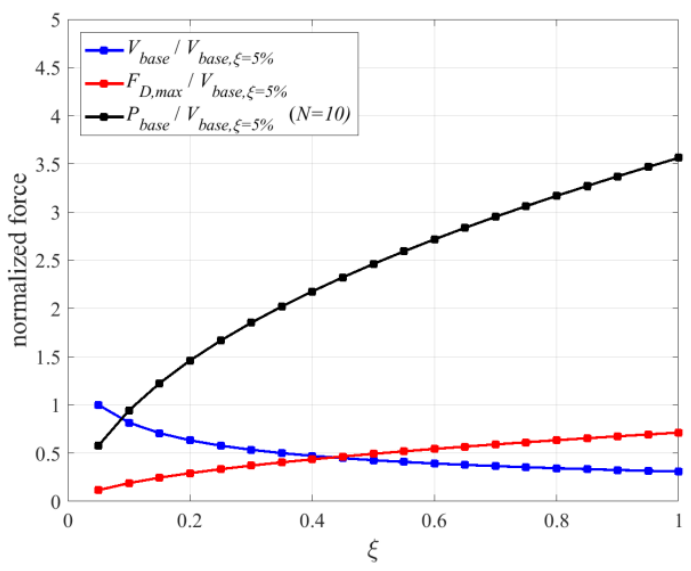

(b)

Figure 8: Base shear, maximum damper force and base axial force: (a) $N=5$, (b) $N=10$.

It is finally of practical interest to directly evaluate the amount of damper force necessary to obtain a certain reduction in the base shear $\Delta V_{\text {base }}=V_{\text {base }, \xi=5 \%}-V_{\text {base }}$.

Substitution of Eq. (2) in Eq. (27) allows to express the ratios $F_{D \text {, max }} / V_{\text {base, },=5 \%}$ and $F_{D \text {,max }} / \Delta V_{\text {base }}$ as functions of $\eta$ :

$$
\frac{F_{D, \max , L}}{V_{b a s e, \xi=5 \%}}=2 \cdot \frac{\left(10-5 \eta^{2}\right)}{\eta \cdot \cos \theta}
$$

$$
\frac{F_{D, \max , L}}{\Delta V_{\text {base }}}=2 \cdot \frac{\left(10-5 \eta^{2}\right)}{(1-\eta) \cdot \eta \cos \theta}
$$

10 Fig. 9a displays $F_{D, \max , L} / V_{\text {base }, \xi=5 \%}$ versus $\eta$, whilst Fig. 9b displays $F_{D, \max , L} / \Delta V_{\text {base }}$ versus $1-\eta$, for $\theta=30^{\circ}$. Fig.9a illustrates the cost (in terms of maximum damper force normalized with respect to $V_{b a s e, \xi=5 \%}$ ) of achieving a prescribed performance (in terms of damping reduction factor). Fig.9b illustrates the cost/benefit ratio (i.e. maximum damper force normalized with respect to $\Delta V_{\text {base }}$ ) corresponding to a prescribed reduction in the response parameter (i.e. $1-\eta$ ). For $1-\eta$ between 0.15 and 0.7 (e.g. $\eta$ between 0.3 and 0.85 ), the ratio $F_{D, \max , L} / \Delta V_{\text {base }}$ is less than 1.0 and almost stable for $1-\eta$ between 0.2 and 0.6 (e.g. $\eta$ between 0.4 and 0.5 ) meaning that the benefit in terms of reduction of base shear is superior than the cost expressed by the maximum damper force. 


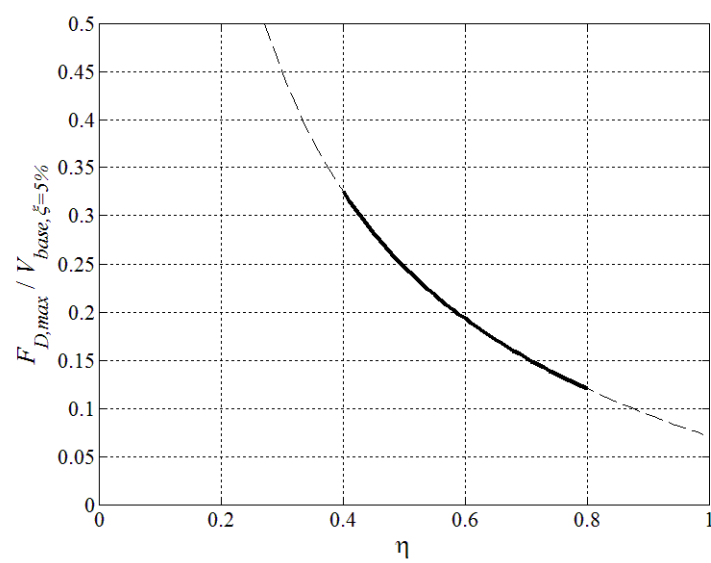

(a)

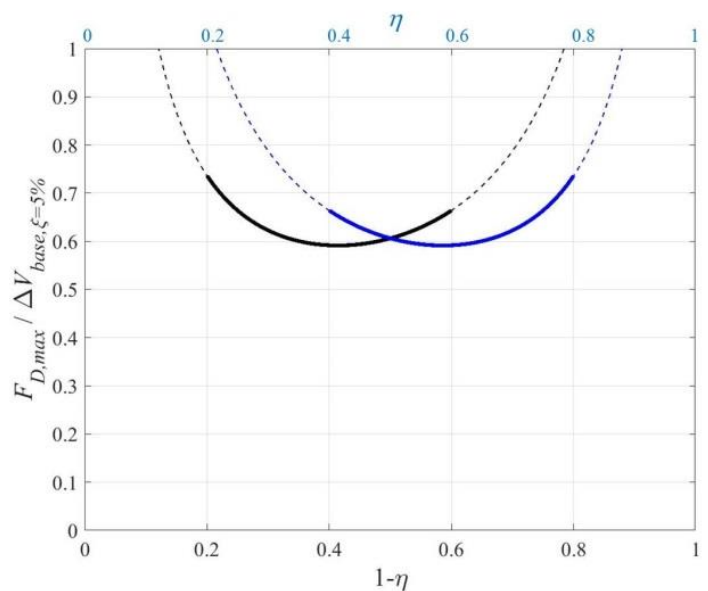

(b)

Figure 9: (a) $F_{D, \max , L} / V_{\text {base }, \xi=5 \%}$ versus $\eta$; (b) $F_{D, \max , L} / \Delta V_{\text {base }}$ versus $1-\eta$

\section{Applicative examples}

In the present section, two applicative example are developed. First, the example frame 3S-90, extensively studied by Ramirez et al. (2003), is considered as reference naked structure. Uniform along-the-height interstorey linear viscous dampers are designed according to the "direct five-step procedure". Then a 10-storey moment resisting frame equipped with non-linear viscous dampers of different sizes is analysed.

\subsection{Example 1: 3S-90 reference frame by Ramirez et al. (2003)}

Frame 3S-90 (Ramirez et al. (2003)) is a 3- storey, 3-bay planar steel frame characterized by a constant bay width equal to $8.23 \mathrm{~m}$ and inter-storey heights equal to $4.42 \mathrm{~m}$ at the ground storey and $4.304 \mathrm{~m}$ at the second and third inter-storey (a constant $\theta=27^{\circ}$ is assumed, given that the differences in the inter-storey heights are negligible). Columns have constant W14x145 cross sections, while cross sections of the beams vary along the height and are equal to W21x44, W18x40, W14x26 at the first, second and roof floor, respectively. The seismic tributary weight is equal to $2900 \mathrm{kN}$ at the first and second floor and equal to 1567 $\mathrm{kN}$ at the roof, leading to a total seismic weight of roughly $7500 \mathrm{kN}$, including the frame self-weight.

\subsubsection{The FE models and the seismic input}

A finite element model of the frame has been developed using the commercial software SAP2000 v17.1. The non-linear behaviour of the frame is modelled through plastic hinges located at both beams and columns ends assuming an elastic-perfectly plastic material behaviour (steel yield stress is assumed equal to $390 \mathrm{MPa}$, Young modulus is set equal to $210000 \mathrm{MPa}$ ). The fundamental period is equal to $1.55 \mathrm{~s}$. The capacity curve of the naked structure in terms of base shear vs. top-storey lateral displacement has been evaluated through non-linear static analysis (pushover) using an inverted triangular distribution of lateral forces. The maximum base shear capacity resulting from the pushover analysis is approximately equal to $1500 \mathrm{kN}$ (Fig. 10a). 
1 A set of 10 artificial ground motions compatible with EC8 design spectrum have been generated using 2 SIMQUAKE (Vanmarcke et al. 1990) to perform the non-linear time history analyses. The individual elastic 3 response spectra and the mean spectrum (with 5\% damping ratio), are shown in Fig. 9b. The records are

4 5 6 7 8 9
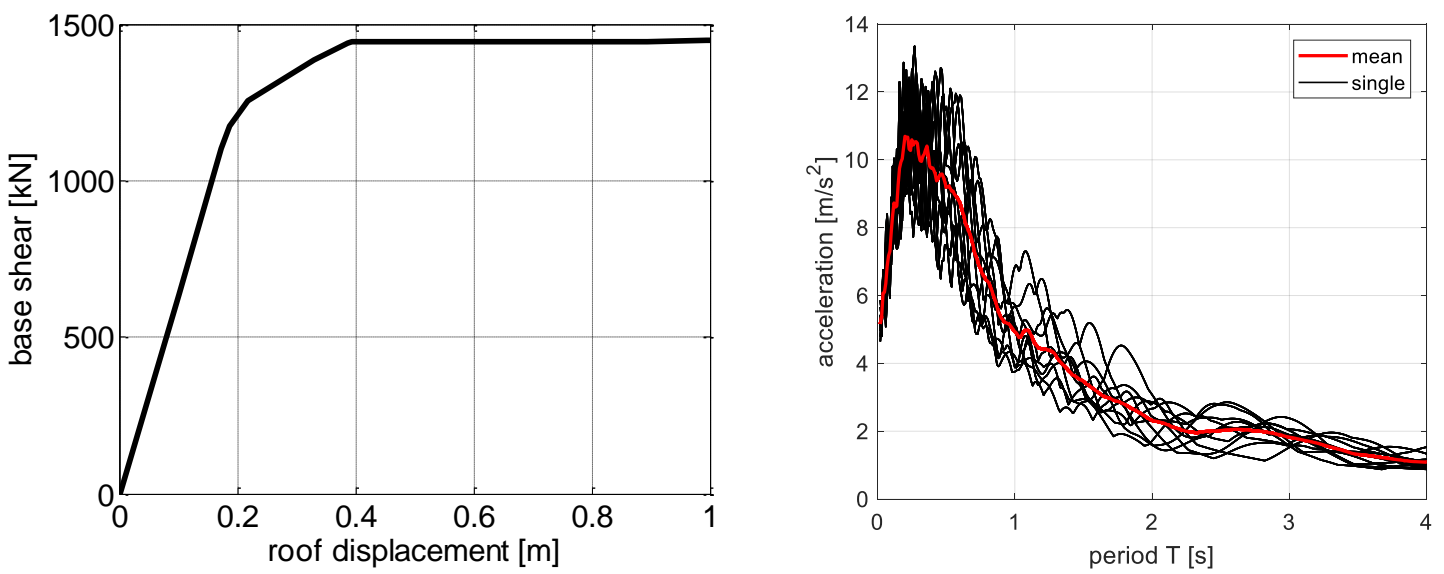

Figure 10: (a) Capacity curves of the different frames from pushover analyses; (b) Response spectra of the 10 artificial accelerograms (black lines) and average spectrum (red thick line).

In the following subsection, the calculations required to apply the procedure are developed in order to give an example to the professional engineer. Both cases of elastic frame response $(\mathrm{q}=1.0)$ and inelastic frame response ( $\mathrm{q}=3.0)$ are encompassed. The considered FE models are listed in Table 1. The inelastic frame response is obtained by scaling up the ordinates of the acceleration records of a factor equal to 3.0. According to this approach the average elastic pseudo-acceleration, at the fundamental period, in the case of the E1Bx3_NL inelastic frame $(\mathrm{q}=3.0)$ is equal to $1.0 \mathrm{~g}$.

Table 1: The FE models of Example 1 frame with and without added dampers.

\begin{tabular}{|c|c|c|c|}
\hline Model name & Damper type & Frame behaviour & Scaling factor \\
\hline E1Dx1-L/L & Linear dampers & Linear & 1.0 \\
\hline E1Dx3-L/L & Linear dampers & Linear & 3.0 \\
\hline E1Dx3-L/NL & Linear dampers & Non-linear & 3.0 \\
\hline E1Bx1-L & No dampers (Bare frame) & Linear & 1.0 \\
\hline E1Bx3-L & No dampers (Bare frame) & Linear & 3.0 \\
\hline E1Bx3-NL & No dampers (Bare frame) & Non-linear & 3.0 \\
\hline
\end{tabular}


2 For the sake of conciseness, hereafter the calculations are explicitly developed just for model E1Dx1-L/L (a 3 unitary behaviour factor $\mathrm{q}=1.0$ is assumed).

4 STEP 1:

5 A target viscous damping ratio $\bar{\xi}_{v}=0.20$ is assumed (in the preliminary design stage $\psi$ is set equal to 1.0 ).

6 As such, the total force reduction factor results equal to (from Eq. 2):

$$
\bar{\eta}(\bar{\xi})=\sqrt{\frac{10}{5+5+20}}=0.58
$$

8 This means that the peak displacements of the damped system are expected to be equal to $58 \%$ of the ones of 9 the corresponding bare frame system, or equivalently that the displacement response is reduced of $42 \%$.

10

11

12

STEP 2:

Assuming equal dampers at all stories, the linear damping coefficient of each damper results equal to (from Eq. 22):

$$
c_{L}=\frac{0.20 \cdot(2 \pi / 1.55) \cdot(7500 / 9.81) \cdot(3+1)}{\cos \left(27^{\circ}\right)^{2}}=3131 \mathrm{kN} \cdot \mathrm{s} / \mathrm{m}
$$

\section{STEP 3:}

The normalized first mode shape as obtained from the modal analysis (Figure 11) has been used to evaluate the structural response of the model according to the procedure detailed in section 3. Table 2 reports the predictions of peak floor displacements, inter-storey velocities and maximum damper forces. Note that $M_{i}$ and $r_{\mathrm{i}}$ values are set equal to 1.0 , while $\lambda$ is set equal to 0.85 .

$\left\{\phi^{1}\right\}$

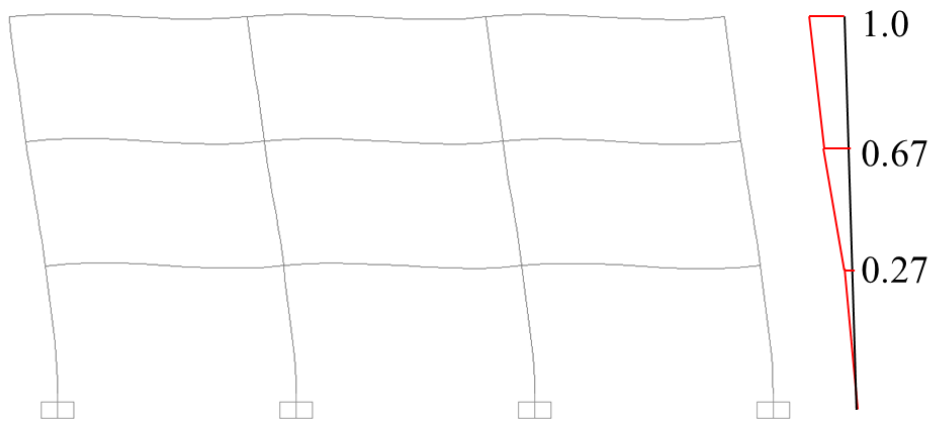

Figure 11: First mode shape for model Dx1_L (maximum value is normalized to 1.0).

Table 2: Predictions of the peak responses, model E1Dx1-L/L. 


\begin{tabular}{|c|c|c|}
\hline Peak response quantity & Storey & Predictions \\
\hline Floor displacement [m] & 1 & 0.04 \\
& 2 & 0.10 \\
& 3 & 0.15 \\
\hline Inter-storey velocities & 1 & 0.16 \\
[m/s] & 2 & 0.24 \\
& 3 & 0.20 \\
\hline Damper forces [kN] & 1 & 472 \\
& 2 & 692 \\
& 3 & 566 \\
\hline
\end{tabular}

STEP 4:

3 Since linear fluid viscous dampers are assumed, the $\alpha$ exponent is equal to 1.0 and the damping coefficient 4 of the damper is equal to the linear damping coefficient $c_{L}$ as evaluated in STEP 2 (Eq. 22).

5 The minimum required axial stiffness of the dissipative brace results equal to (from Eq. 15):

$$
k_{\text {axial }} \geq 10 \cdot 3131 \cdot(2 \pi / 1.55)=7728 \mathrm{kN} / \mathrm{m}
$$

7

8

STEP 5:

The two equivalent lateral force distributions to be used to perform the equivalent static analyses ESA1 and ESA2 are illustrated in Fig. 12.

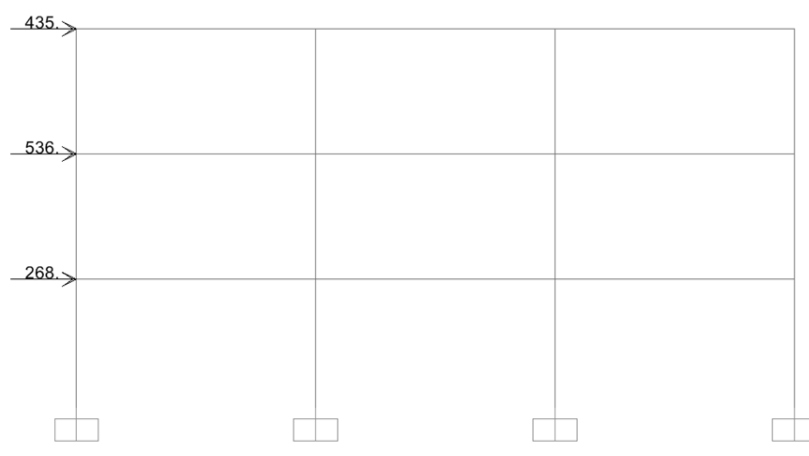

(a)

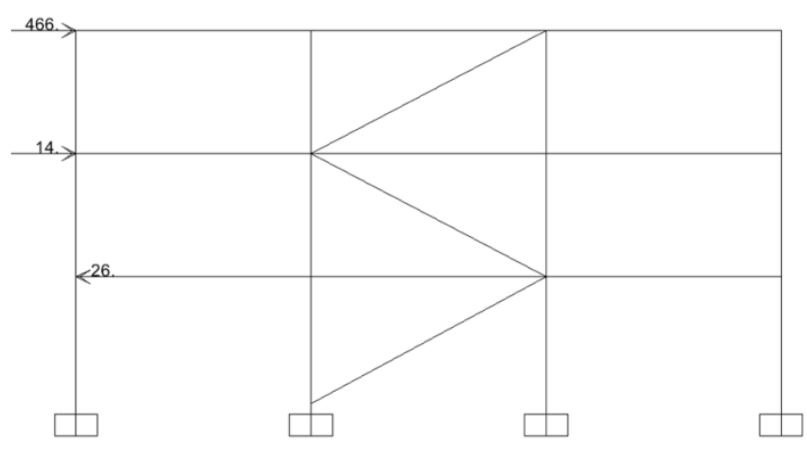

(b)

Figure 12: (a) Equivalent lateral forces according to ESA1; (b) Equivalent lateral forces according to ESA2.

\subsubsection{Final verification through time history analyses}

Non-linear time-history simulations have been performed to compare the predicted peak responses with the results of the numerical simulations. First, the global responses of all models in terms of average (over the 10 time-histories) base shear, $\mathrm{V}_{\text {base }}$, vs. average (over the 10 time-histories) maximum roof displacement, $\mathrm{D}_{\text {roof }}$, as obtained from the time-history simulations, are graphically represented in Fig. 12a, together with the 
pushover curve of the bare frame. The blue arrows compare the responses of models with and without added dampers. In all cases the reduction of the peak roof displacement due to the presence of the viscous dampers is larger than 50\%. The green arrows compare the responses of non-linear and corresponding linear model. It can be noted that the model E1Bx3-NL exploit a full inelastic response with a base shear reduction of 2.6 times with respect to the linear response. The black arrow indicates the whole reduction. The base shear is reduced of 3.1 times, while the top-storey displacement is reduced of 2.4 times. The two red arrows indicate the following two reductions: base shear of the bare frame over yielding strength $\left(\eta_{q}=V_{\text {base }, B} / V_{\text {base }, y}\right)$ and roof displacement of the damped frame with respect to the yielding displacement $\left(\eta_{\xi}=D_{\text {roof }, D} / D_{\text {roof }, y}\right)$. The histogram reported in Figure 13b summarizes the values of the reduction factors of the base shear and of the roof displacement as obtained from the numerical simulations for the unscaled seismic input and the magnified seismic input, respectively. The reductions are computed as the ratio between the peak response quantity of the damped structure and the peak response quantity of the linear bare frame.
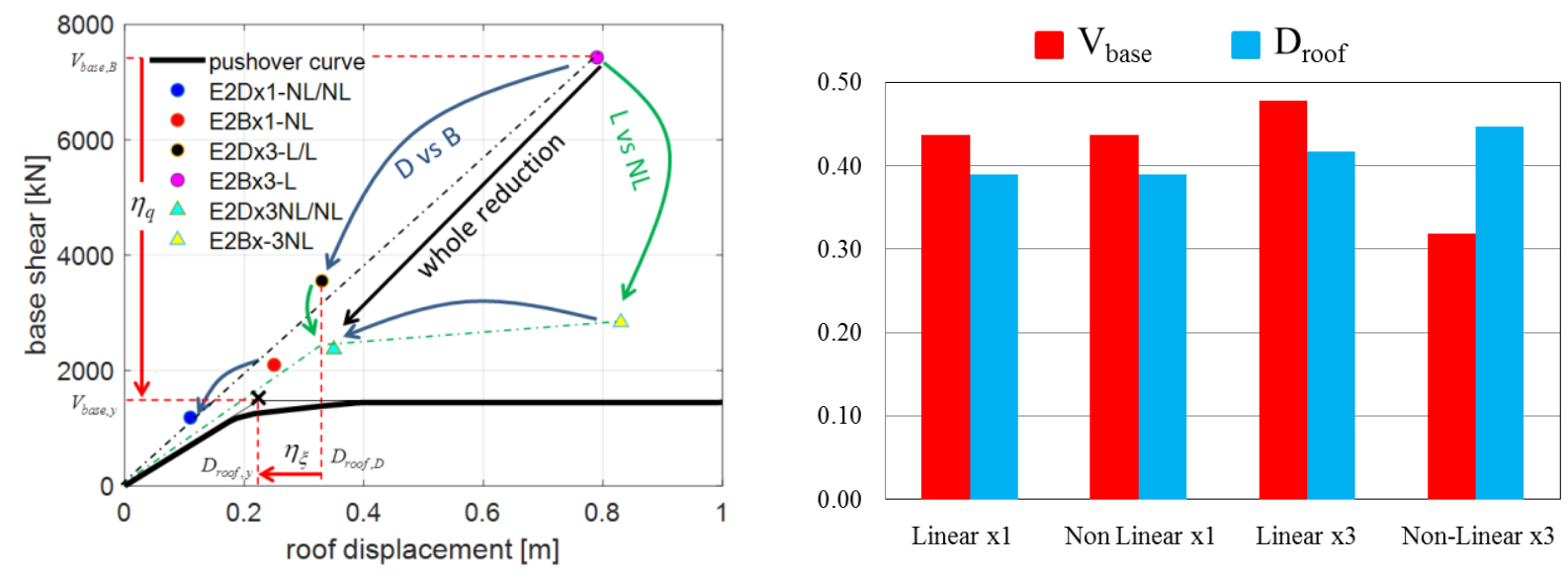

Figure 13: (a) Force displacement responses from pushover analysis and time-history analyses. (b) Histogram of the base shear and peak roof displacement reduction factors.

Tables 3 and 4 compare selected response parameters as obtained from the non-linear time-history analyses with the predictions of STEP 3 for the models E1Dx1-L/L and E1Dx3-L/NL, respectively. Included in the tables are: (a) peak inter-storey drifts, (b) peak inter-storey velocities, (c) peak damper forces.

It can be noted that the predictions of the peak storey drifts are conservative, especially at the roof storey. On the contrary the peak inter-storey velocities are under-estimated at the ground storey, while are conservative at the roof storey. This is due to the fact that in this example case all $M_{i}$ and $r_{i}$ values are set equal to 1.0, while results of previous studies developed by the authors (Palermo et al. 2017) indicates that $M_{i}$ values tends to be larger at the bottom stories and reduces at the top stories. Nonetheless, since a comprehensive parametric study is necessary to calibrate such coefficients (accounting, for instance, for different structural configurations and seismic inputs) a constant (along-the-height) unitary value has been chosen. This is the reason why the accuracy in the prediction of peak floor displacement and velocities is rather limited. 
Table 3: Main response quantities (model E1Dx1-L/L).

\begin{tabular}{|c|c|c|c|c|}
\hline Peak response quantity & Storey & $\begin{array}{c}\mathrm{TH} \\
\text { (non-linear time- } \\
\text { history results) }\end{array}$ & $\begin{array}{c}\mathrm{P} \\
\text { (predictions) }\end{array}$ & $\begin{array}{c}\frac{\mathrm{P}-\mathrm{TH}}{\mathrm{TH}} \\
\text { (relative error) }\end{array}$ \\
\hline Floor displacements [m] & 1 & 0.04 & 0.04 & 2 \\
& 2 & 0.08 & 0.10 & 25 \\
& 3 & 0.11 & 0.15 & 36 \\
\hline Inter-storey velocities [m/s] & 1 & 0.22 & 0.16 & -25 \\
& 2 & 0.23 & 0.24 & 5 \\
& 3 & 0.16 & 0.20 & 24 \\
\hline Damper forces [kN] & 1 & 625 & 472 & -24 \\
& 2 & 640 & 692 & 8 \\
& 3 & 458 & 566 & 24 \\
\hline
\end{tabular}

2

Table 4: Main response quantities (model E1Dx3-L/NL).

\begin{tabular}{|c|c|c|c|c|}
\hline Peak response quantity & Storey & $\begin{array}{c}\text { TH } \\
\text { (non-linear time- } \\
\text { history results) }\end{array}$ & $\begin{array}{c}\text { P } \\
\text { (predictions) }\end{array}$ & $\begin{array}{c}\frac{\mathrm{P}-\mathrm{TH}}{\mathrm{TH}} \\
\text { (relative error) }\end{array}$ \\
\hline Floor displacements [m] & 1 & 0.11 & 0.13 & 14 \\
& 2 & 0.24 & 0.31 & 29 \\
& 3 & 0.33 & 0.46 & 39 \\
\hline Inter-storey velocities & 1 & 0.63 & 0.50 & -20 \\
{$[\mathrm{~m} / \mathrm{s}]$} & 2 & 0.62 & 0.73 & 18 \\
& 3 & 0.43 & 0.60 & 40 \\
\hline Damper forces [kN] & 1 & 1790 & 1416 & -21 \\
& 2 & 1762 & 2077 & 18 \\
& 3 & 1218 & 1699 & 40 \\
\hline
\end{tabular}

4

5 The peak internal actions as obtained from the two equivalent static analyses and from the average response

6 over the 10 time history analyses performed on model E1Dx1-L/L are compared in Figure 14. The blue

7 diagrams refer to the equivalent static analyses, while the red diagrams refer to a specific time-history. Note

8 that in Figure 14a the blue diagram represents the response (shear) as obtained from ESA1 only, while in

9 Figure 14b the two blue diagrams represent the response (axial load) as obtained from ESA1 and ESA2,

10 respectively. Indeed, in general, the peak axial forces in the members should be computed as the envelope of

11 ESA1 and ESA2, as explained in section 8. In this case it can be noted that the discrepancies are within 10\%

12 so that the accuracy of the predictions is acceptable for structural engineering purposes. 


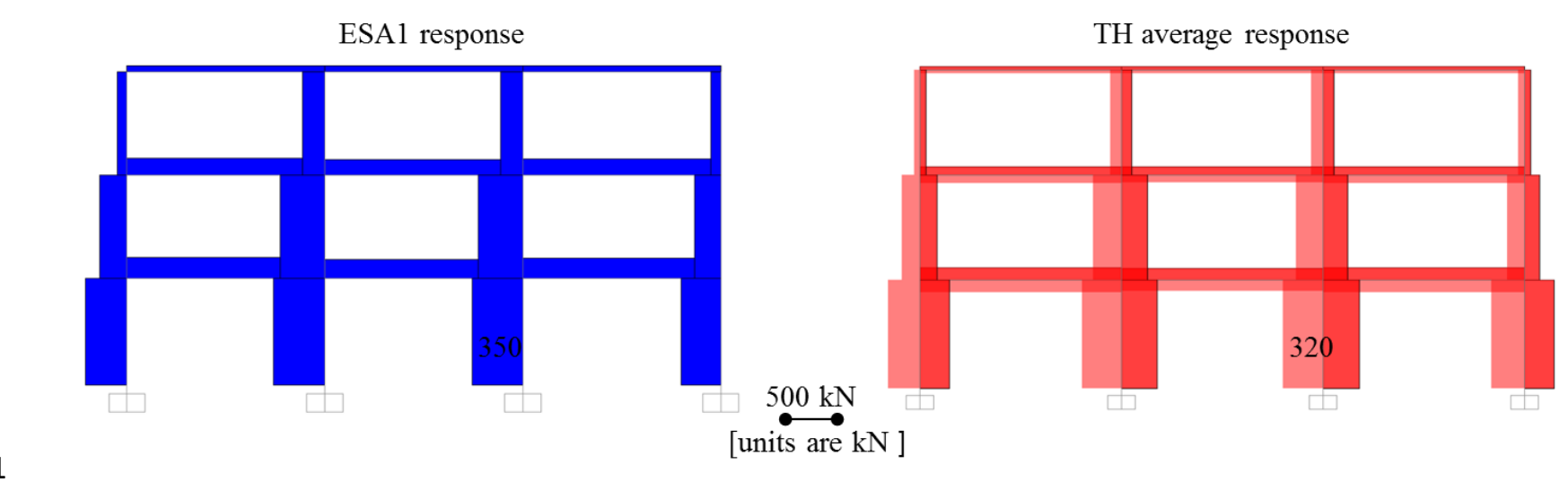

(a)
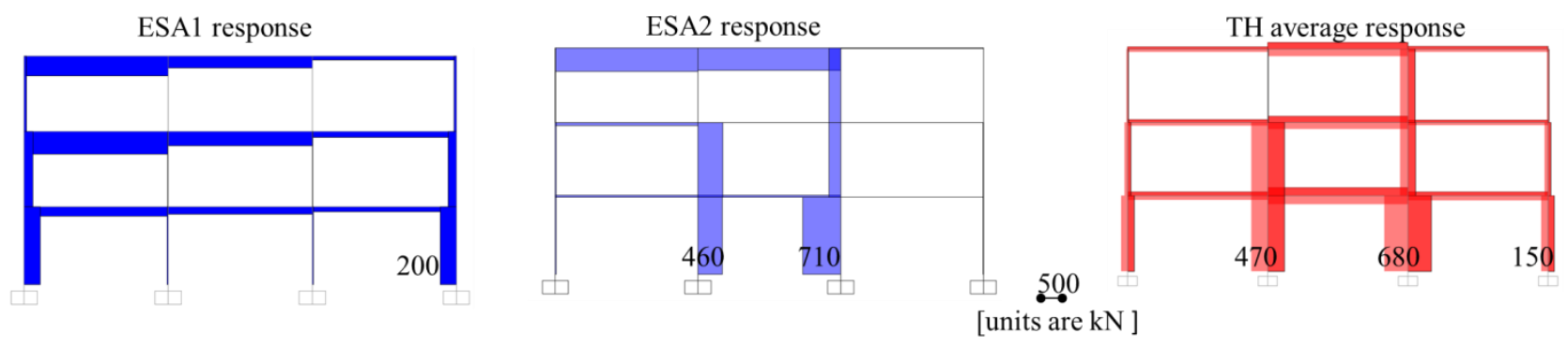

(b)

Figure 14: Comparison of the peak internal actions from the ESA procedure (blue diagrams) and from the average response over the 10 time history analyses (red diagrams): (a) shear force diagrams; (b) axial force diagrams.

\subsection{Example 2: 10-storey frame}

Example 2 is a 10-storey steel framed structure supposed to be located in a high risk seismic region of south Italy. The building has a regular plan with constant span width of $6.00 \mathrm{~m}$. The building height is $35 \mathrm{~m}$ with a constant inter-storey height $\mathrm{H}=3.5 \mathrm{~m}$. The frames are composed by columns and beams with $\mathrm{HE}$ and IPE cross section profiles, respectively. Rigid connections between columns and beams are considered. At each floor a total vertical load (dead loads plus live loads) of $10 \mathrm{kN} / \mathrm{mq}$ is considered. The building seismic weight results equal to 1080 ton. It is assumed to make use of commercial viscos dampers characterized by a damping exponent $\alpha=0.15$ with two different sizes along the building height: one for the first five bottom storey, the other for the remaining five top stories. The plan view, elevation and dampers disposition are displayed in Figure 15. 


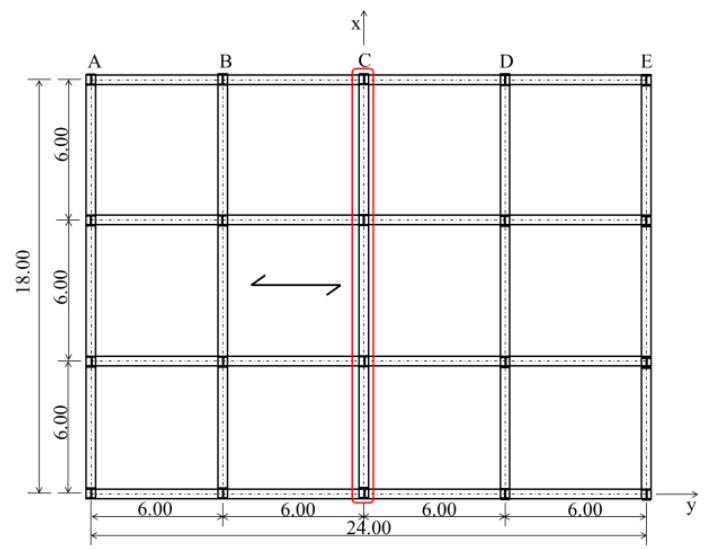

(a)

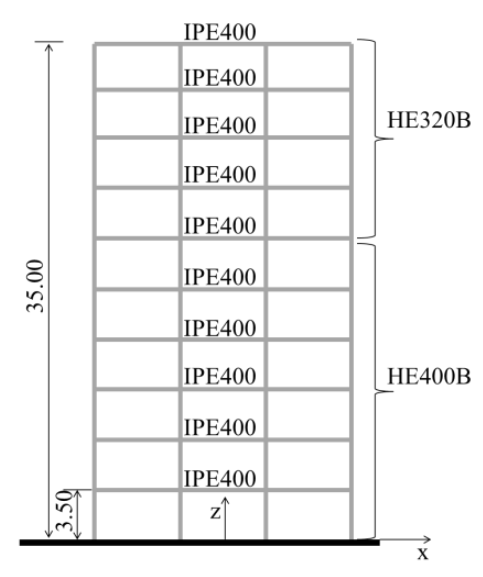

(b)

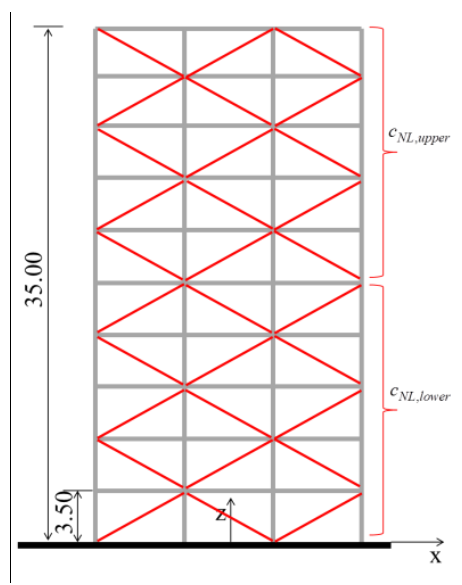

(c)

Table 5: The FE models of Example 2 frame with and without added dampers.

\begin{tabular}{|l|l|l|l|}
\hline Model name & Dampers type & Frame behaviour & Scaling factor \\
\hline E2Dx1-NL/NL & Non-Linear & Non-Linear & 1.0 \\
\hline E2Dx3-L/L & Linear & Linear & 3.0 \\
\hline E2Dx3-NL/NL & Non-Linear & Non-linear & 3.0 \\
\hline E2Bx1-NL & n.a (Bare frame) & Non-Linear & 1.0 \\
\hline E2Bx3-L & n.a (Bare frame) & Linear & 3.0 \\
\hline E2Bx3-NL & n.a (Bare frame) & Non-linear & 3.0 \\
\hline
\end{tabular}




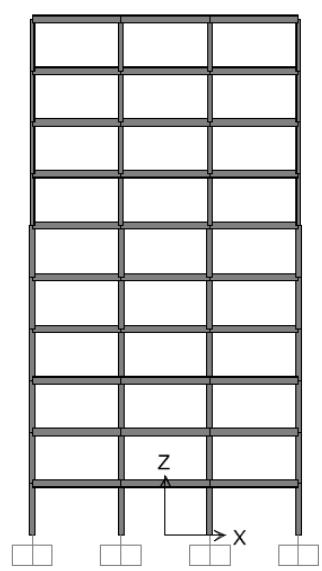

(a)

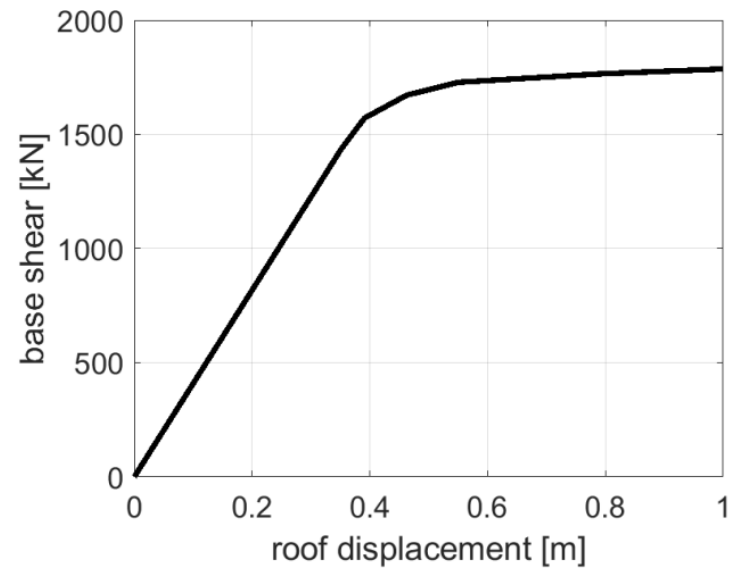

(b)

Figure 16: Example 2 frame: (a) SAP2000 bare frame model. (b) Pushover curve.

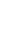

\subsubsection{Application of the "direct five-step procedure" to E2Dx1_NL-NL model}

For the sake of conciseness, hereafter the calculations are explicitly developed for model E2Dx1_NL-NL (a unitary behaviour factor $q=1.0$ is assumed since no significant excursions into the inelastic field are expected).

\section{STEP 1:}

Assuming a target viscous damping ratio $\overline{\xi_{v}}=0.25$, Eq. 2 leads to:

$$
\bar{\eta}(\bar{\xi})=\sqrt{\frac{10}{5+5+25}}=0.53
$$

This means that the peak displacements of the damped system are expected to be equal to $53 \%$ of the ones of the corresponding bare frame system, or equivalently that the displacement response is reduced of $47 \%$.

\section{STEP 2:}

The ratio between the equivalent linear damping ratio of the two damper sizes is set equal to $\frac{c_{L, u p p e r}}{c_{L, \text { lower }}}=\frac{2}{3}$. According to this assumption, the use of Eq. 3 leads to $c_{L, \text { lower }}=3217 \mathrm{kN} \mathrm{s} / \mathrm{m}$ and $c_{L, \text { upper }}=2144 \mathrm{kN} \mathrm{s} / \mathrm{m}$.

\section{STEP 3:}

The normalized first mode shape as obtained from the modal analysis has been used to evaluate the structural response of the model according to the procedure detailed in section 3. Table 6 reports the predictions of peak floor displacements, inter-storey velocities and maximum damper forces. Note that the values of $M_{i}$ at 
1 all stories are set equal to 2.2 (according to Eq. 7 of Palermo et al. 2017), $r_{\mathrm{i}}$ values are set equal to 1.0, while $2 \lambda$ is set equal to 0.85 .

3 Table 6: Prediction of the peak floor displacements and peak inter-storey velocities (E2Dx1_NL-NL model).

\begin{tabular}{|c|c|c|}
\hline Storey & $\begin{array}{c}\text { Floor displacements } \\
{[\mathrm{m}]}\end{array}$ & $\begin{array}{c}\text { inter-storey velocities } \\
{[\mathrm{m} / \mathrm{s}]}\end{array}$ \\
\hline 1 & 0.023 & 0.097 \\
\hline 2 & 0.063 & 0.174 \\
\hline 3 & 0.107 & 0.189 \\
\hline 4 & 0.150 & 0.185 \\
\hline 5 & 0.190 & 0.171 \\
\hline 6 & 0.225 & 0.155 \\
\hline 7 & 0.260 & 0.150 \\
\hline 8 & 0.287 & 0.117 \\
\hline 9 & 0.307 & 0.083 \\
\hline 10 & 0.318 & 0.049 \\
\hline
\end{tabular}

5 STEP 4:

6 Non-linear fluid viscous dampers are assumed with $\alpha$ exponent set equal to 0.15 . Since only two different

7 damper sizes are intended to be used, the values of the non-linear damping coefficients $c_{N L, \text { lower }}$ and $c_{N L, \text { upper }}$ 8 corresponding to $c_{L, \text { lower }}$ and $c_{L, \text { upper }}$ are calculated using Eq. 13 with the average working velocity $\mathrm{v}_{\max }$ as 9 per Eq. 26 magnified with a constant $\mathrm{M}$ factor equal to 2.2 at all stories. As such, the values of the damping 10 coefficient of the non-linear commercial dampers result equal to $c_{N L, \text { lower }}=314 \mathrm{kN}(\mathrm{s} / \mathrm{m})^{0.15}$ and $c_{N L, \text { upper }}=471$ $11 \mathrm{kN}(\mathrm{s} / \mathrm{m})^{0.15}$. The minimum required axial stiffness of the dissipative brace results equal to (from Eq. 15) $12 \quad k_{\text {axial }}=42500 \mathrm{kN} / \mathrm{m}$.

13 STEP 5:

14 The two sets of equivalent lateral force to be used to perform the equivalent static analyses ESA1 and ESA2 15 are graphically shown in Fig. 17. 


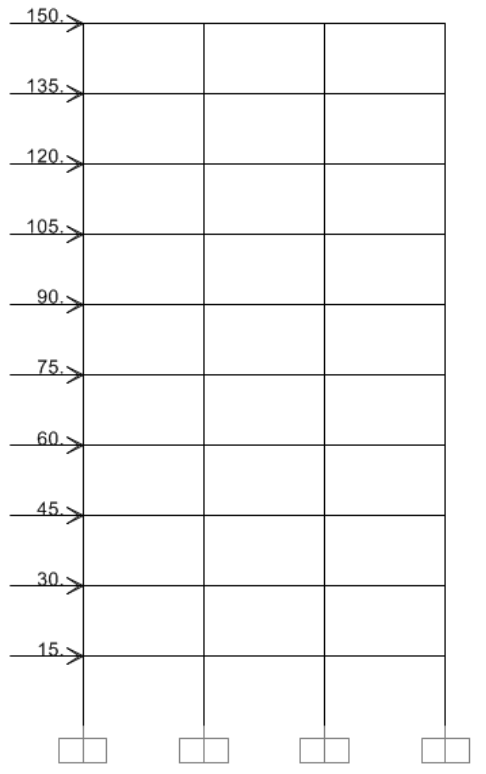

(a)

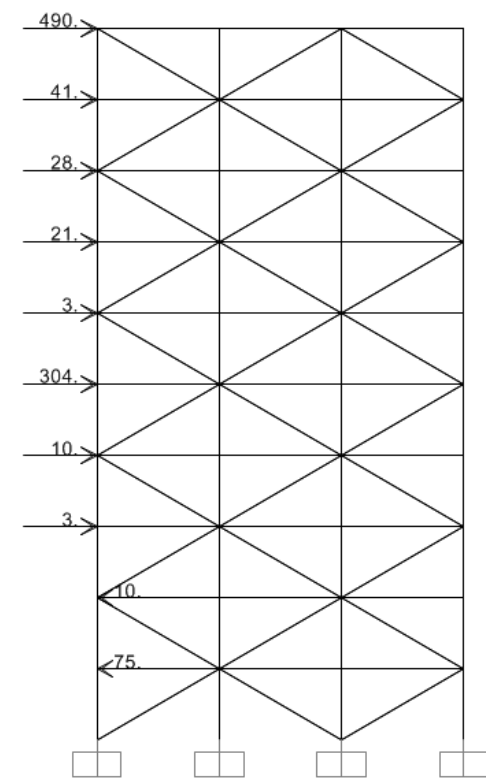

(b)

3 Figure 17: (a) Equivalent lateral forces according to ESA1; (b) Equivalent lateral forces according to ESA2.

\subsubsection{Final verification through time history analyses}

6 Fig. 18a displays the global responses of all models in terms of average (over the 10 time-histories) base shear vs. average (over the 10 time-histories) maximum roof displacement, as obtained from the time-history simulations, together with the pushover curve of the bare frame. Figure 18b displays the histogram of the reduction factors of the base shear and of the roof displacements for the unscaled seismic input (both results of linear and non-linear models) and the magnified seismic input (both results of linear and non-linear models). For both linear models (e.g. linear dampers and linear elastic frames), the base shear and roof displacement are reduced of the same amount (roughly 2.5 times). For the non-linear models (e.g. non-linear dampers and non-linear frames), the values of the base shear reduction are similar to the ones observed for the linear models (around 0.4 corresponding to a reduction of roughly 2.5 times), while the roof displacement is reduced of more than 3 times. 


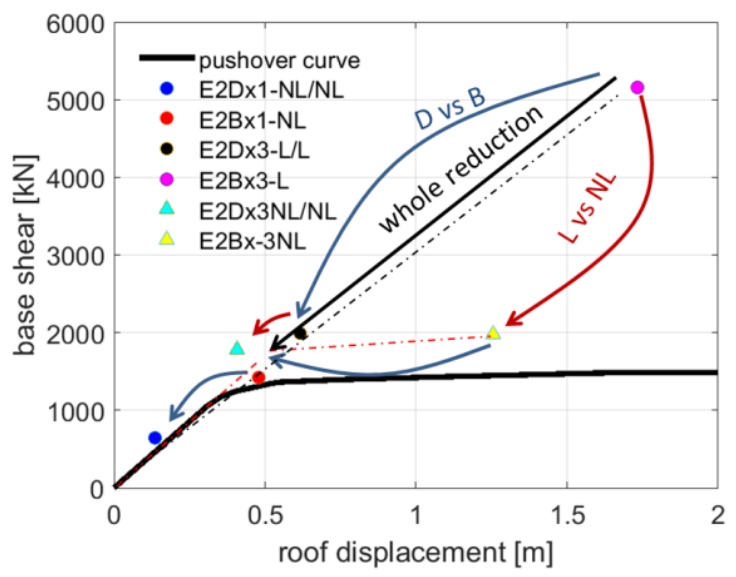

(a)

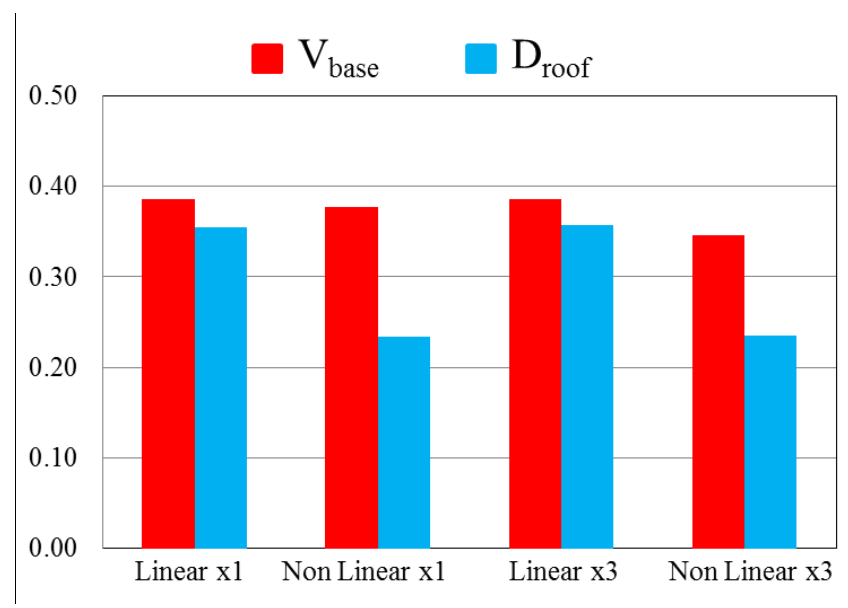

(b)

Figure 18: (a) Force displacement responses from pushover analysis and TH analyses; (b) Histogram of the base shear and peak roof displacement reduction factors.

Figures 19 displays the along the height profile of the peak forces in the viscous dampers as obtained from the numerical simulations (average values over the 10 time-histories) and according to the direct-five step procedure for models E2Dx1_L/L and E2Dx3_L/L models (Figures 19a) and E2Dx1_NL/NL and E2Dx3_NL-NL models (Figures 19b). It can be noted that the assumption of equal values of $\mathrm{M}=2.2$ at all stories leads to an overestimation of the peak damper forces, especially in the upper stories of the linear cases (Figure 19a). This is in line with previous results obtained by the authors in previous works (Palermo et al. 2017) which revealed that for long period structures the maximum inter-storey velocity magnifications are concentrated in the few bottom stories. In order to have less conservative estimations of the peak forces at the upper stories, it is convenient to use values of the $M$ factor closer to 1.0. However, as mentioned in section 4, the accurate estimation of the peak-inter-storey velocities is out of the scope of the previous work and will be the objective of a future study. In the non-linear cases (Figure 19b) the peak damper forces can be more accurately predicted since the damper forces in the range of large velocities are less sensible to a change in the velocity (see the force-velocity represented diagram in Figure 5b). The sudden variation of the along-the-height profiles depends on the variation in the value of the non-linear damping coefficient above the fifth storey. The discrepancies between the predictions and the average response of the non-linear time history analyses are due to the fact that the values of all non-linear damping coefficients are computed making use of a kind of "average" inter-storey velocity (namely equal values at all stories) in the step 4 of the "direct five-step procedure". Again, in case of an accurate estimation is required, a more precise estimation of the maximum velocities in the non-linear dampers can be used (see the original "five-step procedure" by Silvestri et al. 2010). 


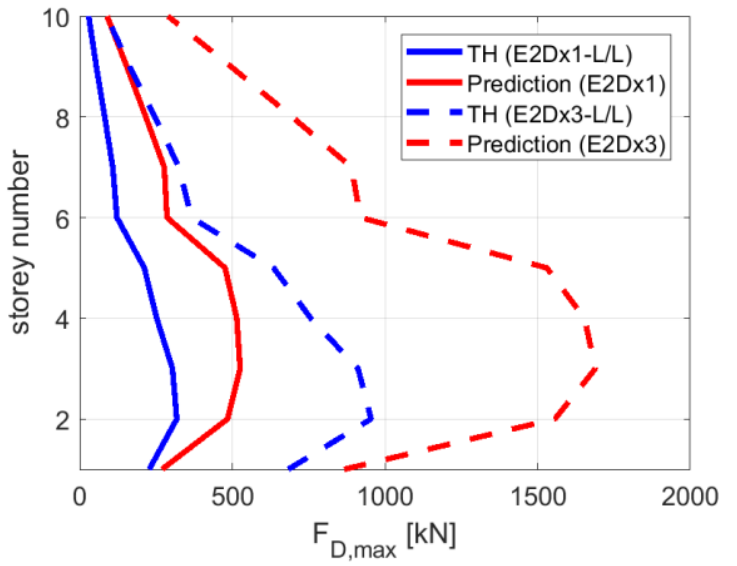

(a)

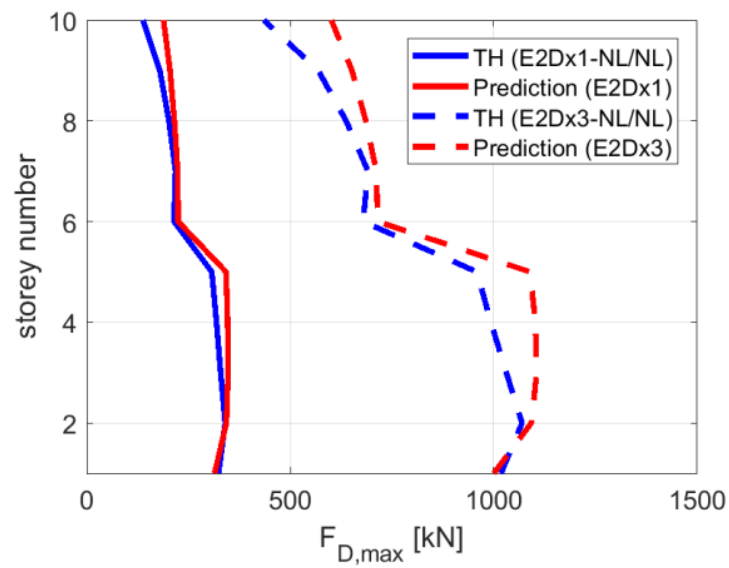

(b)

Figure 19: $\mathrm{F}_{\mathrm{D}, \max }$ profiles from: (a) linear TH analysis; (b) non-linear TH analysis.

Figures 20a and b display the peak floor displacements profiles and the maximum damper velocity profiles, respectively, as obtained from the numerical simulations (average values over the 10 time-histories) and according to the direct-five step procedure for E2Dx1-NL/NL, E2Dx1-L/L, E2Dx3-NL/NL and E2Dx3-L/L models. It can be noted that the estimations of the peak floor displacements are conservative at all stories. On the contrary the peak inter-storey velocities are quite well estimated at the two bottom stories, while they become too conservative at the upper stories. This is again due to simplified assumption of equal magnification factor $M=2.2$ at all stories.
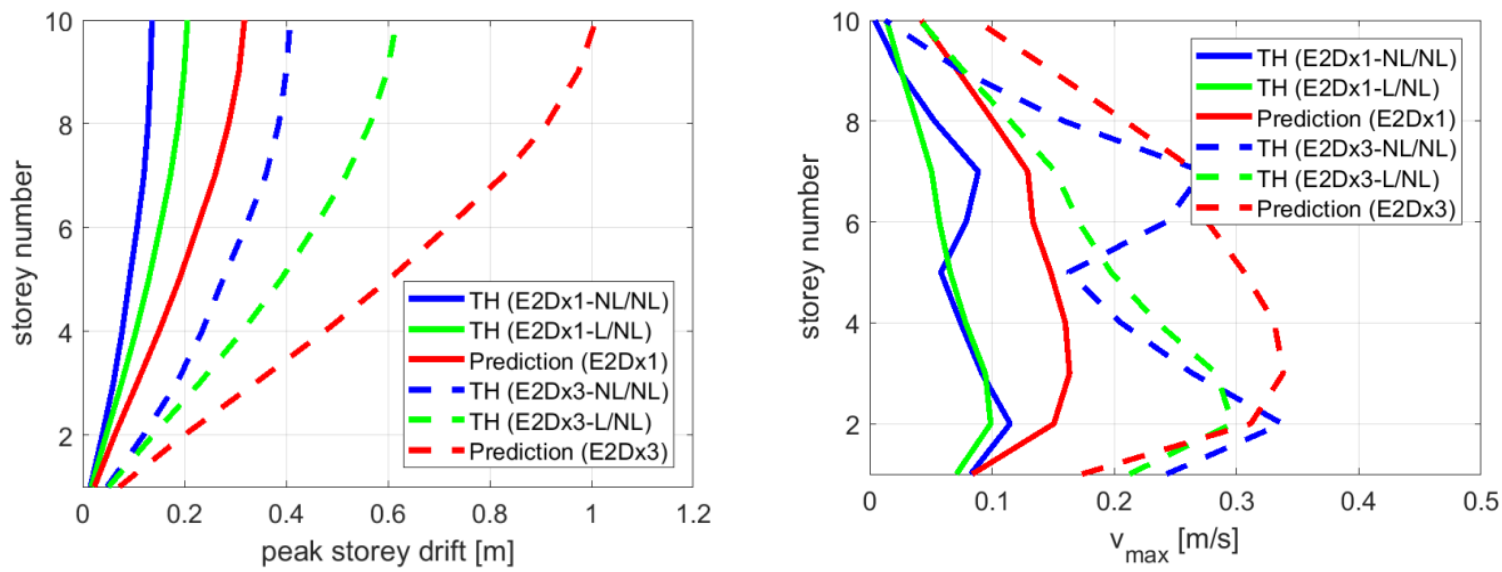

Figure 20: (a) peak floor displacements profiles; (b) $\mathrm{v}_{\max }$ profiles.

Figure 21 compares the peak internal axial forces in the structural members (beams and columns) as obtained from the two equivalent static analyses and from the average response over the 10 time history analyses performed on model E1Dx3-NL/NL. Note that, the estimation of the peak axial forces according to the equivalent static procedure here proposed, is the result of the envelope of the two diagrams obtained from the ESA1 and ESA2 analyses. In this case it can be noted that the discrepancies are within $20 \%$ so that the accuracy of the predictions can be considered acceptable for preliminary design purposes. 


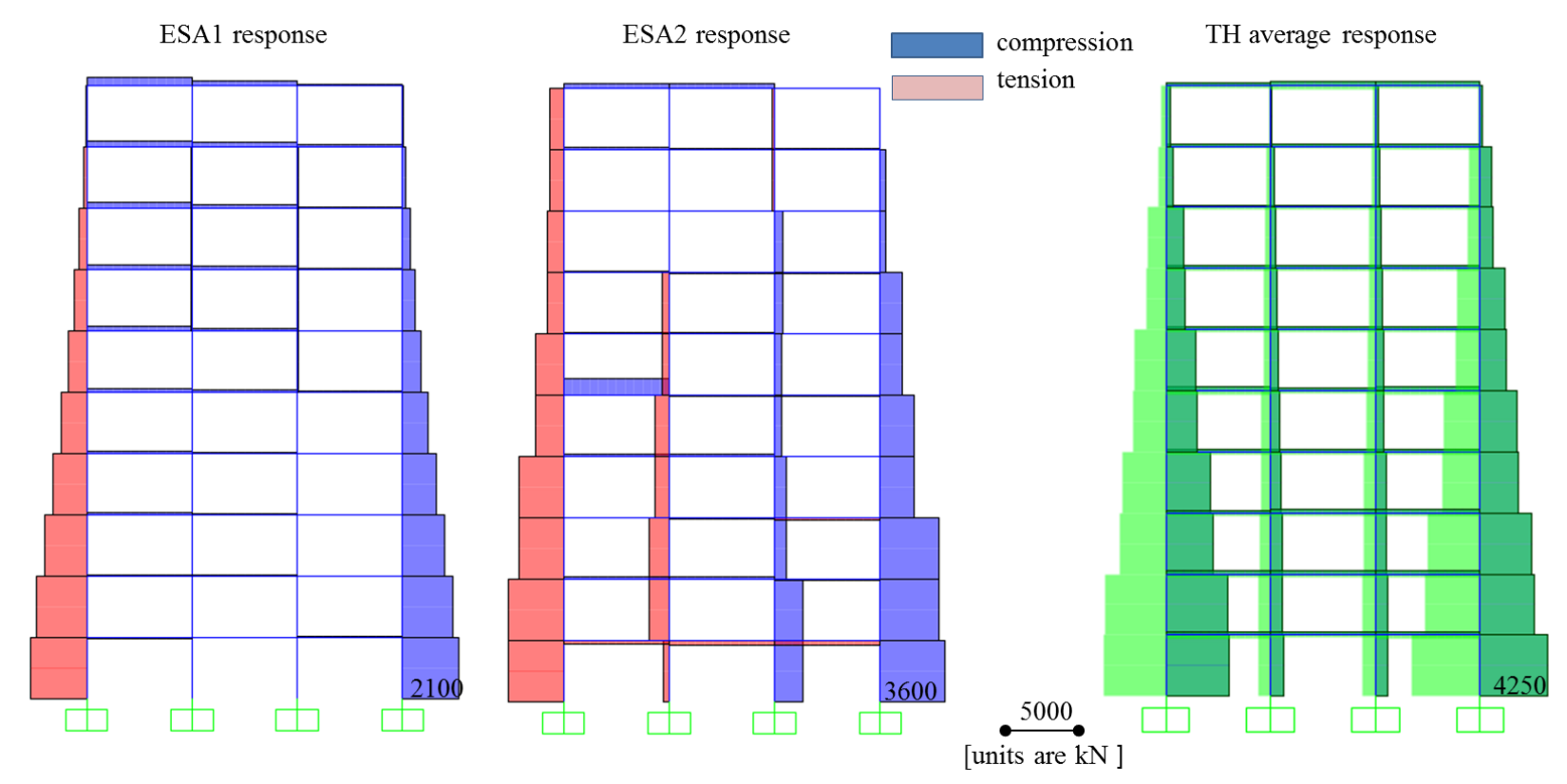

Figure 21: Axial forces as obtained from ESA1, ESA2 and from the average response over the 10 time history analyses.

A "direct five-step design procedure" for the preliminary seismic design of frame structures equipped with inter-storey viscous dampers has been presented. The procedure is aimed at guiding the structural engineer from the choice and sizing of the added viscous dampers to the evaluation of peak internal actions in both dampers and members for their preliminary sizing. It allows to obtain direct estimations/predictions of peak floor displacements, peak inter-storey drifts and velocities, maximum forces in the dampers and maximum internal actions in the structural elements with no need of developing numerical dynamic time history analyses. The proposed estimates are based on an assumed elastic first mode shape modified through various correction coefficients accounting for higher modes contributions and inelastic frame behaviour. Although the procedure can be further improved through an accurate calibration of those correction coefficients (accounting for higher modes contribution, non-linear frame behaviour), it produces results of sufficient accuracy for the sake of preliminary design of regular moment-resisting frames. Nonetheless, at the present stage, the final design has to be developed through non-linear time history analyses. Thanks to its simplicity, the proposed procedure can be very helpful to professional engineers not dealing everyday with the seismic design of structures equipped with added viscous dampers and are not expert with the development of computer based time-history analyses. At the same time it may be also used as simple tool to check the results of more complex design procedures or even time-history numerical simulations. 
Financial supports of Department of Civil Protection (DPC-Reluis 2014-2018 Grant-Research line 6: "Seismic isolation and dissipation") is gratefully acknowledged.

We would like to also thank the two anonymous reviewers for their suggestions and comments, which contribute to significantly improve the quality of the paper.

(1)

\section{REFERENCES}

1. Adachi F, Fujita K, Tsuji M, Takewaki I (2013) Importance of interstory velocity on optimal alongheight allocation of viscous oil dampers in super high-rise buildings. Eng Struct 56:489-500.

2. ASCE/SEI (ASCE/Structural Engineering Institute). (2016). "Minimum design loads for buildings and other structures." ASCE/SEI 7-16, Reston, VA..

3. Building Seismic Safety Council BSSC (1997a) NEHRP Guidelines for the Seismic Rehabilitation of Buildings, FEMA 273, developed by ATC for FEMA, Washinton D.C.

4. Building Seismic Safety Council BSSC (1997b) NEHRP Commentary on the Guidelines for the Seismic Rehabilitation of Buildings, FEMA 274, developed by ATC for FEMA, Washinton D.C.

5. Bommer JJ, Elnashai AS, Weir AG (2000) Compatible acceleration and displacement spectra for seismic design codes. In: Proceedings of the 12th World Conference on Earthquake Engineering. Auckland, New Zealand.

6. Building Seismic Safety Council BSSC (2001) NEHRP Recommended Provisions for Seismic Regulations for New Buildings and other Structures, 2000 Edition, FEMA 368 developed by BSSC for FEMA, Washinton D.C.

7. Building Seismic Safety Council BSSC (2004) NEHRP Recommended Provisions for Seismic Regulations for New Buildings and other Structures, 2003 Edition, FEMA 450, developed by BSSC for FEMA, Washinton D.C.

8. Building Seismic Safety Council BSSC (2005), NEHRP Improvement of Nonlinear Static Seismic Analysis Procedures, FEMA 440, developed by ATC for FEMA, Washington D.C.

9. CEN (2003) Eurocode 8. Design of Structures for Earthquake Resistance - Part 1: General Rules, Seismic Actions and Rules for Buildings, Brussels. 
10. Chopra AK (2001) Dynamics of structures. Theory and applications to earthquake engineering. Prentice-Hall, Upper Saddle River

11. Christopoulos C, Filiatrault A (2006) Principles of passive supplemental damping and seismic isolation. IUSS Press, Pavia.

12. Constantinou MC, Symans MD (1992) Experimental and analytical investigation of seismic response of structures with supplemental fluid viscous dampers. Technical Report NCEER-92-0032, National Center for Earthquake Engineering Research, Buffalo, New York.

13. Constantinou MC, Symans MD (1993) Seismic response of structures with supplemental damping. Structural Design of Tall Buildings 2, 77-92.

14. Green NB (1987) Earthquake resistant building design and construction. Elsevier Publishing Company.

15. Japan Society of Seismic Isolation JSSI (2003) Manual, Design and Construction Manual for Passively Controlled Buildings, First Edition, Tokyo, Japan.

16. Japan Society of Seismic Isolation JSSI (2007) Manual, Design and Construction Manual for Passively Controlled Buildings, Second Edition and Second Print, Tokyo, Japan.

17. Kasai K, Kibayashi M (2004) JSSI manual for building passive control technology. Part-1 manual contents and design/analysis methods, 13th World Conference on Earthquake Engineering, Vancouver, B.C., Canada, Paper No. 2989.

18. Landi L, Pollio B, Diotallevi PP (2014) Effectiveness of different standard and advanced pushover procedures for regular and irregular RC frames, Structural Engineering and Mechanics, 51(3), 433446.

19. Levy R, Lavan O (2006) Fully stressed design of passive controllers in framed structures for seismic loadings, Struct. Multidiscip. Optimiz., 32(6),485-498.

20. Lopez Garcia D (2001) A simple method for the design of optimal damper configurations in MDOF structures. Earthquake Spectra, 17 (3), 387-398.

21. NTC (2008) Norme Tecniche per le Costruzioni, Italian building code, adopted with D.M. 14/01/2008, published on S.O. n. 30 G.U. n. 29 04/02/2008.

22. Palermo M, Muscio S, Silvestri S, Landi L, Trombetti T (2013a) On the dimensioning of viscous dampers for the mitigation of the earthquake-induced effects in moment-resisting frame structures, Bulletin of Earthquake Engineering, 11(6), 2429-2446.

23. Palermo M, Silvestri S, Trombetti T, Landi L (2013b) Force reduction factor for building structures equipped with added viscous dampers, Bulletin of Earthquake Engineering, 11(5), 1661-1681. 
24. Palermo M, Silvestri S, Gasparini G, Trombetti T (2015). Seismic Modal Contribution Factors, Bulletin of Earthquake Engineering,13(10), 2867-2891.

25. Palermo M, Silvestri S, Landi L, Gasparini G, Trombetti T (2016) Peak velocities estimation for a direct five-step design procedure of inter-storey viscous dampers, Bulletin of Earthquake Engineering, 14(2), 599-619.

26. Palermo, M., Silvestri, S., \& Trombetti, T. (2017). On the peak inter-storey drift and peak interstorey velocity profiles for frame structures. Soil Dynamics and Earthquake Engineering, 94, 18-34.

27. Papanikolaou VK, Elnashai AS, Parejia JF (2006) Evaluation of conventional and adaptive pushover analysis II: comparative results, Journal of Earthquake Engineering, 10(1), 127-151.

28. Ramirez OM, Constantinou MC, Whittaker AS, Kircher CA, Chrysostomou CZ (2002) Elastic and inelastic seismic response of buildings with damping systems. Earthquake Spectra, 18(3), 531-547.

29. Ramirez OM, Constantinou MC, Whittaker AS, Kircher CA, Johnson MW, Chrysostomou CZ (2003). Validation of the 2000 NEHRP provisions' equivalent lateral force and modal analysis procedures for buildings with damping systems. Earthquake Spectra, 19(4), 981-999.

30. Ramirez OM, Constantinou MC, Kircher CA, Whittaker AS, Johnson MW, Gomez JD, Chrysostomou CZ (2001) Development and evaluation of simplified procedures for analysis and design of buildings with passive energy dissipation systems, Report MCEER-00-0010, State University of New York at Buffalo.

31. Seismology Committee (1974) Recommended Lateral Force Requirements and Commentary, Structural Engineers Association of California, San Francisco.

32. Shukla AK, Datta TK (1999) Optimal use of viscoelastic dampers in building frames for seismic force. Journal of Structural Engineering, ASCE, 125 (4), 401-409.

33. Silvestri S, Gasparini G, Trombetti T (2010) A five-step procedure for the dimensioning of viscous dampers to be inserted in building structures, Journal of Earthquake Engineering, 14(3), 417-447.

34. Singh MP, Moreschi LM (2002) Optimal placement of dampers for passive response control. Earthquake Engineering and Structural Dynamics, 31, 955-976.

35. Takewaki I (1997) Optimal damper placement for minimum transfer functions, Earthquake Engineering and Structural Dynamics, 26, 1113-1124.

36. Takewaki I (2000) Optimal damper placement for critical excitation, Probabilistic Engineering Mechanics, 15, 317-325.

37. Takewaki I (2009) Building Control with Passive Dampers: Optimal Performance-based Design for Earthquakes, John Wiley \& Sons (Asia), Singapore. 
38. Trombetti T, Silvestri S (2004) Added viscous dampers in shear-type structures: the effectiveness of mass proportional damping, Journal of Earthquake Engineering, 8(2), 275-313.

39. Trombetti T, Silvestri S (2006) On the modal damping ratios of shear-type structures equipped with Rayleigh damping systems, Journal of sound and vibration, 292(1), 21-58.

40. Vanmarcke EH, Cornell CA, Gasparini DA, Hou S (1990) SIMQKE-I: simulation of earthquake ground motions. T.F. Blake, Newbury Park, California, Department of Civil Engineering, Massachusetts Institute of Technology, Cambridge, Massachusetts

41. Weng D G, Zhang C, Lu X L, Zeng S, Zhang SM (2012) A simplified design procedure for seismic retrofit of earthquake-damaged RC frames with viscous dampers. Structural Engineering and Mechanics, 44(5), 611-631.

42. Whittaker AS, Constantinou MC, Ramirez OM, Johnson MW, Chrysostomou CZ (2003) Equivalent lateral force and modal analysis procedures of the 2000 NEHRP Provisions for buildings with damping systems. Earthquake Spectra, 19(4), 959-980. 


\section{APPENDIX 1: dynamics of a damped SDOF portal frame}

Let us consider the single-storey portal frame equipped with a viscous damper incorporated in a diagonal member inclined at an angle $\theta$ with respect to the horizontal direction and subjected to a horizontal ground acceleration $\ddot{u}_{g}(t)$, as depicted in Fig. $m$ is the total mass of the system, $k$ is the lateral stiffness. A1. Let us assume that the beam is infinitely rigid and the diagonal member (upon which the damper is installed) is axially inextensible. On the contrary, let us consider the axial deformability of the columns, which allows the vertical displacements of nodes $\mathrm{C}$ and $\mathrm{D}$ and the rigid rotation of the beam. By lumping the beam mass in node $\mathrm{C}$ and by condensing the displacements of node $\mathrm{D}$, the system can be idealized as the 2-DOF system represented in Fig. A1. The two degrees of freedom are the horizontal displacement $u_{h}$ of node C (beam) and the vertical displacement $u_{v}$ of node $\mathrm{C}$. The circular frequency of the first mode of vibration (translational mode along the horizontal direction) is $\omega_{h}$ and the corresponding period of vibration is: $T_{1}=\frac{2 \pi}{\omega_{h}}$.

The dynamic equilibrium equations of the 2-DOF system can be written as follows:

$$
\left\{\begin{array}{l}
f_{I h}+f_{D h}+f_{S h}=0 \\
f_{I v}+f_{D v}+f_{S v}=0
\end{array}\right.
$$

or, equivalently:

$$
\left\{\begin{array}{l}
m \ddot{u}_{h}+c_{h} \dot{u}_{h}+c_{h v} \dot{u}_{v}+k_{h} u_{h}=-m \ddot{u}_{g}(t) \\
m \ddot{u}_{v}+c_{h v} \dot{u}_{h}+c_{v} \dot{u}_{v}+k_{v} u_{v}=0
\end{array}\right.
$$

where $f_{I h}$ and $f_{I V}$ are the inertia forces along the horizontal and the vertical directions, respectively; $f_{D h}=f_{D} \cdot \cos \theta$ and $f_{D v}=f_{D} \cdot \sin \theta$ are the damping forces along the horizontal and the vertical directions, respectively; $f_{S h}$ and $f_{S v}$ are the elastic (or restoring) forces along the horizontal and the vertical directions, respectively; $m$ is the mass; $k_{h}$ and $k_{v}$ are the horizontal and the vertical translational stiffness of the frame; $c$ is the damping coefficient of the linear viscous damper; $c_{h}=c \cdot \cos ^{2} \theta, c_{h v}=c \cdot \cos \theta \cdot \sin \theta$ and $c_{v}=c \cdot \sin ^{2} \theta$ can be easily determined by applying the direct method (Chopra 2001) to the damping forces; $\ddot{u}_{g}(t)$ is the earthquake ground acceleration along the horizontal direction.

The presence of the inclined damper couples the motion along the horizontal and vertical directions, even though only the horizontal component of the ground motion is considered. Nonetheless, for common values 
of the $k_{v} / k_{h}$ ratio, it is possible to neglect, in the first equation of the system given by Eq. (A2), the force proportional to the vertical velocity thus leading to the following uncoupled equation:

$$
m \ddot{u}_{h}+c_{h} \dot{u}_{h}+k_{h} u_{h}=-m \ddot{u}_{g}(t)
$$

which is coincident with the standard equation of motion of an SDOF system as subjected to earthquake input. From basic concepts of structural dynamics (Chopra 2001) it is known that, at the time instant $\left(t_{1}\right)$ of maximum horizontal displacement $\left(u_{h}\left(t_{1}\right)=u_{h, \max }\right)$ and maximum horizontal acceleration $\left(\ddot{u}_{h}\left(t_{1}\right)=\ddot{u}_{h, \max }\right)$, the horizontal velocity and the damper force are null $\left(\dot{u}_{h}\left(t_{1}\right)=0\right)$. At this time instant, Eq. (A3) becomes:

$$
m \ddot{u}_{h, \max }+k_{h} u_{h, \max }=-m \ddot{u}_{g}
$$

Where $\ddot{u}_{g}$ indicates the ground acceleration at the time instant $t_{1}$. Eq. A4 can be rewritten as:

$$
m\left(\ddot{u}_{h, \text { max }}+\ddot{u}_{g}\right)=-k_{h} \cdot u_{h, \text { max }}=f_{S h, \text { max }}
$$

The maximum horizontal restoring force $\left(f_{S h, \max }\right)$ is then estimated from the spectral acceleration $S_{e, \xi}\left(T_{1}\right)$ as evaluated at the $T_{1}$ and related to the amount of damping ratio $\xi$ corresponding to the damping coefficient $c$ of the diagonal viscous damper. Eq. (A5) is a static equation whose solution allows to estimate the internal actions at the instant of maximum horizontal displacement. This concept represents the basis of the method of equivalent static forces. It is clear that the effect of the damper is to reduce the maximum horizontal inertia force and thus to reduce the maximum horizontal internal action. If the horizontal peak velocity $\dot{u}_{h \text {,max }}$ is estimated from the velocity spectrum (e.g. $S_{e, \xi}\left(T_{1}\right) \cdot \frac{T_{1}}{2 \pi}$ ) the peak damper force may be obtained as follows:

$$
f_{D, \max }=\frac{c_{h} \cdot S_{e, \xi}\left(T_{1}\right)}{\omega_{h} \cdot \cos \theta}
$$

Once $f_{D}(t)$ is known, the second equilibrium equation of Eq. (A2) can be rewritten as follows:

$$
m \ddot{u}_{v}+c_{v} \dot{u}_{v}+k_{v} u_{v}=-f_{D}(t) \cdot \sin \theta=-f_{D v}(t)
$$

which is the equation of a SDOF system subjected to an external force equal to $f_{D v}(t)$. Rigorously, the determination of the vertical elastic force requires the solution of the above differential equation. The maximum vertical dynamic response is achieved when the damper force is at its maximum value, i.e. at time instant $\left(t_{2}\right)$ of maximum horizontal velocity $\left(\dot{u}_{h}\left(t_{2}\right)=\dot{u}_{h \text {, max }}\right)$, null horizontal displacement $\left(u_{h}\left(t_{2}\right)=0\right)$ 
1 and null horizontal acceleration $\left(\ddot{u}_{h}\left(t_{2}\right)=0\right)$. Nonetheless, given that for common frame structures the

2 vertical stiffness $k_{v}$ is much larger than the horizontal stiffness $k_{h}$ and consequently mode of vibration along

3 the vertical direction has a natural frequency that is a much larger than the one associated to the first mode,

4 the dynamic amplification of the vertical motion (induced by the horizontal motion) can be neglected. AS

5 such, the maximum elastic force along the vertical direction can be estimated through a simple static

6 analysis:

$$
k_{v} u_{v, \max }=f_{D v, \max }=f_{D v} \cdot \sin \theta=c_{h} \cdot \frac{S_{e, \xi}\left(T_{1}\right)}{\omega_{h}} \cdot \tan \theta=2 \cdot \xi_{v} \cdot m \cdot S_{e, \xi}\left(T_{1}\right) \cdot \tan \theta
$$

8 Note that the solution of the static equilibrium Eq. A8 allows to obtain the internal actions which are in 9 equilibrium with the peak damper forces at the instant of maximum horizontal velocity. It is thus clear that 10 such internal actions do not have to be added to the ones obtained from the solution of Eq. A5, since they are 11 referred to different time-instants.

a)

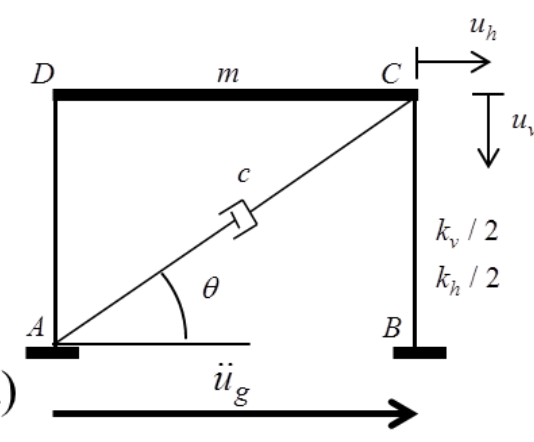

b)

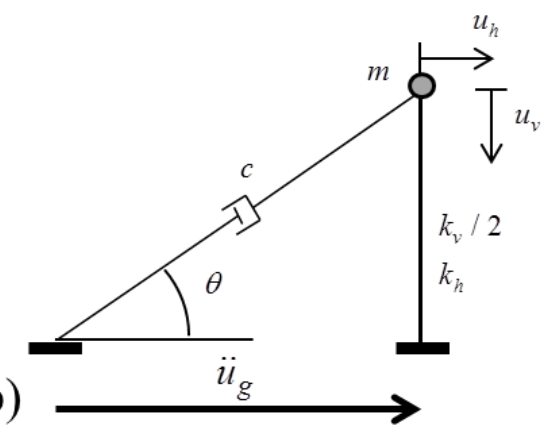

$$
f_{D v, \max }=2 \cdot \xi \cdot m \cdot S_{e, \bar{\xi}}\left(T_{1}\right) \cdot \tan \theta
$$

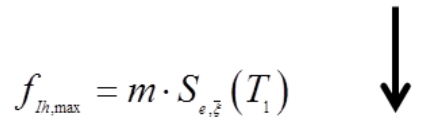

c)

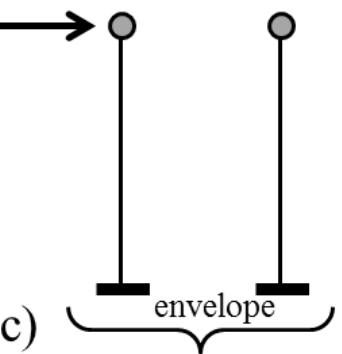

Figure A1: (a) The portal frame with a diagonal viscous damper; (b) the 2-DOF damped system; (c) the two 